\title{
Consideraciones económicas en las relaciones con los concesionarios
}

\author{
Jacinto Vereda Espada \\ Ph. D. in Business \& Applied Economics, \\ Wharton School, Univ. of Penna. USA \\ Técnico Comercial y Economista del Estado
}

En el ámbito de las concesiones administrativas, los desacuerdos entre los concesionarios y la Administración concedente surgen, generalmente, en relación con: la determinación del nivel de tarifas, su revisión y variación, el mantenimiento del equilibrio, la potestad de fiscalizar la concesión. Las normas vigentes son claras, pero malos hábitos han contribuido a que los concesionarios siempre ganen en sus planteamientos. El objetivo de este trabajo es ayudar a la parte concedente a gestionar el conflicto dentro de las normas, con una aplicación directa y llana del alcance de sus artículos pertinentes, cuyo significado, a veces, se ignora o se vela con expresiones grandilocuentes, pero vacuas. Hay información suficiente y asequible para concretar y aplicar expresiones tales como: margen normal de beneficio, una buena y ordenada administración, equilibrio, factores constitutivos de la tarifa como base para futuras revisiones.

\section{INTRODUCCIÓN}

Las disputas económicas entre concesionario y concedente provienen, generalmente, de la determinación de tarifas, de su revisión, de las inversiones a realizar y de la obligación de mantener el equilibrio en la concesión. Con menor frecuencia también surgen discrepancias que giran en torno a los bienes revertibles y al personal del concesionario saliente. A efectos expositivos, los comentarios que siguen se agrupan bajo esos encabezamientos, y se empleará la palabra Ayuntamiento en vez de concedente para aproximar más la exposición a las inquietudes reales de quienes son, en la mayoría de los casos, la parte "concedente" en el lado de la Administración y los "sufridores" de prácticas sesgadas excesivamente a favor de los concesionarios. 
La motivación de estos comentarios es ayudar a interpretar un conflicto, sus raíces, sus soluciones, y los fundamentos para respaldar la postura de cada cual. Los ejemplos aquí mencionados son casos reales surgidos en los cursos sobre concesiones administrativas que el INAP viene ofreciendo desde hace años y en los que he participado como profesor. Del intercambio de experiencias y escarmientos se aprende tanto como de las normas aplicadas con diligencia. Teniendo en cuenta las numerosas incidencias que surgen y el desamparo en el que se encuentran muchos ayuntamientos, sería de enorme utilidad la creación, tal vez dentro del propio INAP, de un grupo asesor sobre concesiones que de forma análoga a como actúa la Junta Consultiva de Contratación Administrativa, atendiera, aconsejara y divulgara su parecer para que sirviera de "botón de muestra" a través de su página de internet, para aprovechar al máximo su efecto multiplicador. A falta de ello, que valga esta exposición para ayudar a los "atrapados" en concesiones heredadas o a quienes prevean que han de redactar pliegos para alguna concesión nueva.

Las normas vigentes (concretamente el RSCL y el TRLCAP) son claras; no hay que esperar a que salgan otras para administrar mejor la relación entre Ayuntamiento y concesionario. La probabilidad de que surjan problemas aumenta cuanto más se apartan los pliegos de dichas normas; pero, aun sin apartarse de ellas, uno ha de ser consciente de su alcance, de su significado. Ocurre a veces que, agobiado por el tiempo y obligaciones, el responsable busca ayuda o busca un atajo, se apoya en pliegos que alguien le pasa, los retoca para adecuarlos a su caso y sale del apuro. Esta costumbre se detecta al leer pliegos en los que se introducen variantes tales como "las tarifas se incrementarán cada año de acuerdo con el IPC", "el Ayuntamiento se compromete a mantener, en todo momento, el equilibrio económico-financiero de la concesión", etc.

Otras veces, se adorna la redacción de los pliegos reproduciendo casi verbatim artículos de las normas, pero apartándose de ellas para no citar palabra por palabra. Sin embargo, como en los libros de recetas de cocina, si allí se emplea dos veces la palabra rehogar, será porque hace falta, y no cabe substituirla por otra, a menos que se quiera, conscientemente, decir otra cosa. En la redacción de los pliegos debe prevalecer el rigor y la claridad, y es un riesgo enorme, si no un claro error, sustituir, por ej., la palabra "ventas" por "ingresos" o ingresos por "beneficios", etc. También debe buscarse la brevedad. Para ello, basta con decir, por ej.: "Aquí se da por trascrito el Art. 127 del RSCL al cual deseamos añadir las precisiones siguientes ..." en vez de escribir parrafadas que sólo son un refrito y no añaden nada distinto de lo contemplado en tal o cual artículo de las normas. 
Por seguridad, uno no debiera apartarse de las normas, a menos que lo haga para mejorarlas, si es que puede. A veces se repiten expresiones grandilocuentes, sin saber lo que significan, imposibles de aplicar o totalmente erróneas, como aquélla que dice "equilibrio económico-financiero"; se copian pliegos, sin adecuarlos, y, al final, surgen las discrepancias (resueltas casi siempre con compromisos o con criterios políticos, que acaban adquiriendo carta de naturaleza).

Los pliegos son como un traje a medida: no son mejores los más largos, los que más entresacan o reproducen parrafadas. Al decir por qué normas se rigen, ya no haría falta reproducirlas, y en ellas estará el cauce para la solución a la disputa.

Las desavenencias entre concesionario y Ayuntamiento que tienen que ver con aspectos económicos pueden agruparse en torno a estos puntos: determinación de las tarifas, su revisión, inversiones a realizar, restablecimiento del equilibrio, que comentamos a continuación.

\section{DETERMINACIÓN DE LAS TARIFAS}

\section{II.1. Copiamos seguidamente el Art. 129.3 del RSCL}

En todo caso, la retribución prevista para el concesionario deberá ser calculada de modo que permita, mediante una buena y ordenada administración, amortizar durante el plazo de la concesión el costo de establecimiento del servicio y cubrir los gastos de explotación y un margen normal de beneficio industrial".

En su momento comentaremos cómo se puede calibrar si existe o no "una buena y ordenada administración" y lo que pudiera considerarse "un margen normal de beneficio". Obsérvese releyendo la cita, que la retribución (cualquiera que sea su forma) ha de ser suficiente para cubrir:

1. Los costes de explotación o costes de producción (a los que el concesionario habrá de hacer frente como cualquier otra empresa del sector privado. A saber: costos de personal, Seguridad Social, gastos financieros, amortización de equipos o de otros activos fijos, transporte, seguros, energía y electricidad, etc.).

2. La amortización -o recuperación- durante el plazo de la concesión del costo de establecimiento del servicio. Es decir, el concesionario habrá de recuperar las inversiones que haya tenido que hacer o que ten- 
ga que hacer para hacerse cargo del servicio. Otras veces, no son inversiones materiales propiamente dichas destinadas a ampliar o mejorar las infraestructuras, sino que es un gasto en forma de canon inicial único o un canon periódico que el concesionario ha de pagar. Comoquiera que, al finalizar la concesión, aquellas infraestructuras revierten al Ayuntamiento, o al ente concedente en general, y aquel canon no se recupera, el concesionario, para no descapitalizarse, va dotando a lo largo de la vida de la concesión un fondo de reversión que le permite acumular suficientes recursos como para recuperar "el costo de establecimiento del servicio". Para evitar equívocos, porque la palabra "amortización" surge en dos contextos contables distintos, la amortización de este punto suele llamarse "amortización financiera" o "dotación al fondo de reversión" y la que aparece como un costo más de producción se llama "amortización material o técnica".

Es decir, la retribución prevista para el concesionario ha de ser suficiente para cubrir los costes de producción del punto 1, la dotación al fondo de reversión del punto 2 para recuperar, durante el plazo de la concesión, el costo de las inversiones y/o canon que haya tenido que hacer para hacerse cargo de la concesión. Y también un "margen normal de beneficio industrial".

En la determinación del nivel de tarifas a veces juega un papel importante el valor de las inversiones que el concesionario lleva a cabo y que tiene que recuperar vía tarifa. El cálculo de su valor puede ser engorroso (no difícil) porque se ejecutan en distintos años y habrá que aplicar el oportuno descuento. En todo caso, en los apéndices técnicos de los pliegos aparecerán las inversiones mínimas y su calendario de ejecución para alcanzar cuanto antes la máxima eficiencia/calidad del servicio. Será un criterio a ponderar tanto si el concursante realiza dichas inversiones por un precio inferior al presupuestado, como si oferta más inversiones realmente necesarias, como si reduce el plazo de ejecución. Debe evitarse que la concesión se convierta en un negocio de hacer obras. Lo importante, siempre, y lo que más debe ponderar en la concesión del servicio es el precio del servicio. Lo demás es subsidiario. En este punto abunda la picaresca de ofertar un volumen mayor de obras para conseguir la adjudicación. Una vez lograda, se retrasan las obras o se "demuestra" que todas ellas no son realmente necesarias. En tal caso, se le debe exigir al concesionario que pague al Ayuntamiento la diferencia entre el valor de las inversiones que ofertó y las que hace (descontando el valor de éstas por el índice de infla- 
ción según el año en que las ejecute, y nunca más tarde del año establecido en el calendario de los pliegos). Obsérvese que, de otro modo, el adjudicatario hubiera podido ser otro.

3. Un margen normal de beneficio industrial. Las tarifas han de ser suficientes para hacer posible que el concesionario obtenga un beneficio, pero no se le asegura que lo obtenga, y tampoco se han de subir las tarifas para que lo obtenga, pues él va a su riesgo y ventura, con la premisa de que ejerce una buena y ordenada administración.

Lo que es un margen "normal" de beneficio industrial puede variar a lo largo de la vida de la concesión, sobre todo si ésta se otorga para un plazo largo; siempre se puede establecerlo en relación, por ej., con el tipo de interés de la deuda pública a cinco o diez años, o en relación con el rendimiento de una cartera teórica del mercado de renta fija AIAF (Asociación de Intermediarios de Activos Financieros), datos publicados con regularidad por el Banco de España (www.bde.es, Boletín Estadístico). Esos rendimientos son los que el concesionario deja de obtener al invertir sus recursos en la concesión (su coste de oportunidad). A ello habrá que añadir equis puntos porcentuales para compensarle por el riesgo, la preocupación y quebraderos de cabeza de gestionar el negocio. Al sacar a concurso la concesión, se establecería como criterio a puntuar el margen de beneficio que el concursante exige y que las tarifas han de hacer posible. A mayor beneficio exigido, menor puntuación. Se trata siempre de hacer posible una remuneración de los recursos propios; no de garantizarla.

Aunque el margen normal de beneficio industrial que se tomó en cuenta para la adjudicación, multiplicado por los Recursos Propios dé una cantidad que también se puede expresar cada año como un porcentaje de los Gastos Totales (y eso es pura aritmética), no se debe definir el margen normal de beneficio como un porcentaje fijo sobre los Gastos Totales. Si el concesionario no obtiene el margen de beneficio que se le admitió y por el que se le puntuó en la adjudicación, no quiere ello decir que haya que subir las tarifas para que lo obtenga. El fue a su riesgo y ventura y si, a pesar de llevar una buena y ordenada administración, no gana o no gana tanto como previó, es su problema.

La lógica del Art. 129.3 del RSCL se puede aplicar a cualquier concesión; la complejidad de su aplicación específica variará (piénsese en la concesión de una autopista frente a la concesión de una cafetería) y ejercer, por parte de la Administración, la potestad de modificar y de fiscalizar o vigilar la gestión de la concesión puede ser una labor ingente o sencilla. 
El Art. 129.3 del RSCL no es restrictivo: la retribución puede consistir sólo en tarifas que abone el público o en tarifas más subvenciones; da cabida a cualquier sistema de tarifas (fijas, mixtas -una parte fija y otra variable-, progresivas por tramos). Es frecuente en las concesiones de suministro domiciliario de agua potable que la tarifa incluya una parte fija para que todos paguen, aunque sólo sea por el mero hecho de tener una acometida y la posibilidad de consumo, y otra variable. La parte fija no debiera superar un porcentaje dado del total de ingresos -o incluso no debiera existir- para evitar que se convierta en un colchón mínimo garantizado que desincentive una buena gestión. Y en cuanto a la parte variable, en el futuro será cada vez más frecuente que la tarifa no sea un precio fijo $/ \mathrm{m}^{3}$ de agua medida en contador, pues, para que la ciudadanía tome conciencia de la importancia de ahorrar un recurso escaso (el agua), se establecen tramos de consumo y, al pasar de un tramo al siguiente, el precio $/ \mathrm{m}^{3}$ aumenta (es decir, la tarifa es progresiva). Para no penalizar a familias numerosas, éstas acreditan esa condición ante el concesionario, que lo registra y toma como referencia el consumo per cápita.

$\mathrm{Al}$ sacar a concurso la concesión de agua, se advierte en los pliegos que el sistema de facturación implantado por el concesionario debe contemplar la posibilidad de que en el futuro se apliquen tarifas progresivas (y de que así se refleje en la factura) sin que ello le dé pie a reclamar compensación alguna en base a un mayor coste. Además, como los costos de producir un $\mathrm{m}^{3}$ de agua no han variado, aunque se introduzca el sistema de tarifas progresivas, los mayores ingresos que se obtienen al aplicar dichas tarifas van a las arcas del Ayuntamiento, pues su misión no es cubrir ningún elemento del punto 1, 2 ó 3 anteriores, sino racionalizar el consumo y castigar el despilfarro.

En otro Ayuntamiento se sacó a concurso el abastecimiento de agua sin tener aún construida la depuradora que obligatoriamente habría de hacer y que sería objeto de otra concesión posterior. Se mencionó en los pliegos que, en el futuro, el adjudicatario tendría que añadir en el recibo del consumo de agua una línea explicitando la cuantía de un canon de depuración por $\mathrm{m}^{3}$, cuyos ingresos serían recaudados por el concesionario del suministro de agua, pero abonados en la cuenta que el Ayuntamiento le indicara, toda vez que el concesionario de la depuradora podría ser distinto del concesionario del agua, pero habida cuenta de que lo que cada consumidor habría de pagar en concepto de depuración dependía del volumen consumido y que la forma más lógica de calcularlo y aplicarlo era mencionándolo y cobrándolo en el propio recibo del agua. 
Es decir, cuando uno se enfrenta a situaciones peculiares, lo menciona en los pliegos para adelantarse y evitarse problemas futuros, extendiéndose cuanto haga falta para tomar precauciones. Otra situación peculiar, ilustrativa de la picaresca, también surgida dentro de una concesión de suministro de agua en un ayuntamiento de Mallorca, nos permite ver que el objeto de la concesión no fue bien definido. En este caso, el concesionario A del suministro de agua aparecía cada año por las oficinas del Ayuntamiento con su abogado, que exponía la marcha de la concesión y argumentaba su petición de subida de tarifas en base a la subida de costes, que eran, básicamente, las subidas del precio del agua "en alta" que a él le aplicaban y que él tenía que repercutir. Curiosamente, la empresa B, propietaria de los pozos y suministradora del agua "en alta”, subía regularmente el precio del m3 de agua suministrado al concesionario A. Pero la empresa B y la A eran propiedad del mismo señor. Al ser jurídicamente distintas, los beneficios se registraban en la empresa $\mathrm{B}$ donde el ayuntamiento no tenía poder de fiscalización, ni de limitar sus beneficios a un margen normal, mientras que la concesionaria A pedía cada año el restablecimiento de su equilibrio. Esta situación se hubiera podido evitar estableciendo que el objeto de la concesión abarcaba todas las etapas de la cadena, desde la perforación de nuevos pozos, captación, afloración, aducción,..., hasta el suministro domiciliario. Ello hubiera obligado a las empresas A y B a presentarse el concurso como una UTE. Cabe tomar medidas legales para salir de esa situación abusiva; pero ése no es el objeto de este trabajo. Esta "anécdota" debiera servir de escarmiento para los municipios donde se prevén aumentos en la población, y donde pudiera darse el caso de que el concesionario, para atender el aumento previsto en la demanda, perfore nuevos pozos; que lo haga, pues, como parte integral de la concesión vigente, y no a través de otra empresa distinta

\section{II.2. El RSCL, Art. 115}

El RSCL, Art. 115 dice cuáles han de ser las cláusulas minimas y su contenido por las que se regirá la concesión y que han de recogerse en los pliegos; la sexta exige que haya unas "tarifas que hubieren de percibirse del público, con descomposición de sus factores constitutivos, como base de futuras revisiones."

1. Esto implica que en los pliegos se pedirá que los concursantes aporten la estructura de sus costes de producción, como base para futuras revisiones, y porque es uno de los tres ingredientes que ha de cubrir la retribución o tarifas que se le aprueben. Posteriormente, si procede, se retocarán las tarifas teniendo forzosamente en cuenta la importan- 
cia relativa de sus factores constitutivos, y la variación al alza o a la baja de los mismos, así como la variación en su importancia relativa, si es que la hubo. Por eso, el decir que "las tarifas se incrementarán anualmente de acuerdo con el IPC", aunque evidentemente su aplicación sea muy cómoda, es una burrada que puede favorecer con desmesura al concesionario. El apartarse de las normas en esos términos es una seria torpeza.

En los pliegos se pide a los concursantes que aporten el desglose de sus costos de explotación o de producción; éstos pueden agruparse en 4 ó 5 epígrafes que representen, en porcentaje, prácticamente el 80\%-90\% del total, más un epígrafe "Otros" para incorporar los de menor importancia y así llegar al $100 \%$ del total. Sirvan como ejemplo los datos del Cuadro I, donde se dan el desglose $(353928+20195+35128+\ldots+11400)$ y el total $(516521)$ de los costos de producción de la empresa XYZ concesionario de abastecimiento de agua. La información de la columna A, hasta el "Total Costos de Producción" sería la que cada uno de los concursantes tendría que aportar, a sabiendas de que servirá de base para futuras revisiones de las tarifas. Las restantes cifras de la columna A, Dotación al Fondo de Reversión (12630) y Beneficios (3600) se fijan posteriormente con los datos del adjudicatario.

\section{Cuadro I}

CONGESIONARIO XYZ DEL ABASTECIMIENTO DE AGUA

\begin{tabular}{l|r|r|r|r}
\hline Conceptos & A & B $(\mathbf{W i})$ & C $(\mathbf{P i})$ & D (WiPi) \\
\hline Sueldos, Salarios y S. Social & 353.928 & 0,66434038 & 0,02 & 0,013286 \\
\hline Gastos financieros y bancarios & 20.195 & 0,03790701 & $-0,009$ & $-0,00034119$ \\
\hline Amortización & 35.128 & 0,06593699 & 0 & 0 \\
\hline Electricidad & 33.714 & 0,06328285 & 0,012 & 0,00075936 \\
\hline Conserv y mantenimiento & 62.156 & 0,11666989 & 0,019 & 0,00221673 \\
\hline Tfno. Comunicaciones, Alquileres y otros & 11.400 & 0,02139836 & 0,092 & 0,0019688 \\
\hline (a) Total Costos Producción & 516.521 & & & 0 \\
\hline (b) Dotación Fondo de Reversión & 12.630 & 0,02370714 & 0 & 0 \\
\hline (c) Beneficios/Recursos Propios & 3.600 & 0,00675738 & 0 & $\mathbf{1}$ \\
\hline Total Cf. RSCL Art. 129.3 & $\mathbf{5 3 2 . 7 5 1}$ & & & $\mathbf{0 , 0 1 7 8 8 9 7}$ \\
\hline
\end{tabular}


2. La retribución (tarifa) que se apruebe ha de ser suficiente, además, para "amortizar durante el plazo de la concesión el costo de establecimiento del servicio". Si a los concursantes no se les exigió inversión alguna, ni canon alguno, este segundo componente sería cero. $\mathrm{Si}$, por el contrario, al adjudicatario se le exigió llevar a cabo inversiones que quedaron cifradas en 352,600, cada año de los veinte que dura la concesión dotará al fondo de reversión $(352600 / 20=12630)$ como en el ejemplo, y si, además, se les exigía pagar un canon y el adjudicatario ofertó pagar 100, amortizará o recuperará o dotará a un fondo de reversión $(100) /(20)=5$ por año, adicionales. La práctica de exigir un canon es aberrante. El adjudicatario lo tiene que recuperar vía tarifas (con lo cual éstas serán más altas de lo que pudieran ser de otro modo). Si de lo que se trata es de prestar un buen servicio al menor costo, no debiera haber canon alguno. A los que argumentan que el canon se cobra porque se le cede al concesionario el uso y disfrute de un dominio público cabe contestarles que también el concesionario se obliga a mantenerlo y conservarlo, y que ha de revertir en perfecto (buen) estado de uso, con lo cual, el concesionario se aprovecha de ello, pero gasta para conservarlo, mantenerlo, y al final lo cede. El quid está en que los ayuntamientos, al cobrar un canon, reciben fondos que pueden gastar, pueden hacer valer para sus fines políticos de cara a unas elecciones, pero con esa costumbre repercuten a los ciudadanos una especie de impuesto oculto.

Las llamadas "prima de adjudicación”, "prestaciones voluntarias en metálico", "canon" constituyen serias irregularidades en el procedimiento ... si se convierten en elementos determinantes a la hora de seleccionar ofertas. Ello puede lindar en actividades delictivas ${ }^{1}$. En el margen, por muy poca ponderación que se le dé a ese criterio en la adjudicación, siempre puede ser determinante, a menos que todos los concursantes oferten la misma cuantía y, por ende, todos reciban los mismos puntos, en cuyo caso, ese criterio no sirve para diferenciar una oferta de otra.

Como la realidad es compleja, también cabe argumentar que cobrar un canon puede ser deseable y, desde luego, no aberrante. Sea el caso de una concesión de abastecimiento de agua cuyas tarifas fueron subiendo con el IPC, porque así estaba estipulado en los pliegos. Al renovar la concesión y es-

\footnotetext{
${ }^{1}$ Informe 44/1995, de 21 diciembre 1995, de la Junta Consultiva de Contratación Administrativa.
} 
tablecer el nivel de tarifa de referencia para el concurso, se ve que la tarifa/ $\mathrm{m}^{3}$ podría ser bastante más baja y, aún así, cubriría los componentes $(\mathrm{a})+(\mathrm{b})$ + (c). El Ayuntamiento decide que es más deseable no bajarla: los usuarios, ya hechos a un precio más alto, alterarían sus hábitos de consumo en un sentido perjudicial para la buena gestión de un bien escaso. Entonces, a sabiendas de que el adjudicatario ingresará más de lo económicamente necesario para su equilibrio, le impone un canon para que recaude y transfiera al Ayuntamiento el "excedente" que el propio concursante calcula y oferta. Todo correcto.

Distinto sería si lo que se le pide al concursante es que haga determinadas inversiones que el Ayuntamiento no puede emprender (porque no tiene suficientes recursos o porque no los puede gastar tan deprisa como exigiría el funcionamiento eficiente de la concesión). En este caso, habrá un apéndice técnico en el que se relacionen todas las inversiones a realizar, su valor total en el período "cero", con su calendario de ejecución, etc. Y toda su cuantía habrá de ser recuperada vía tarifas durante el plazo de la concesión, haciendo la dotación correspondiente al fondo de reversión. Parte de esas inversiones pueden materializarse en la compra de equipos o construcciones que, simultáneamente, se deterioran en el proceso productivo y que habrá que reponer. Por lo tanto, simultáneamente, el concesionario estará amortizando como costos de producción la cuantía necesaria que le permita reponer el bien tantas veces como haga falta dentro de la vida de la concesión (amortización material o técnica), sin dejar de dotar al fondo de reversión para recuperar el costo de establecimiento (amortización financiera).

3. Finalmente, la retribución (tarifa) ha de ser suficiente para cubrir un margen normal de beneficio industrial. $Y$ en este punto también existe una muy mala costumbre que consiste en añadir a los gastos generales (de explotación y dotación al fondo de reversión) un porcentaje, ya sea un $10 \%$ u otro cualquiera, en concepto de beneficio industrial. El concesionario no tendrá interés en que se reduzca la base sobre la que aplica su porcentaje de beneficio. No tendrá interés en que se reduzcan sus costos de explotación; cuanto mayores sean, mayor es su beneficio. Si a esto se añade la rutina de subir las tarifas según el IPC, nos encontramos con sectores en los que se enquista la inflación; en los que es prácticamente imposible contener los precios, y que, para mayor desdicha, se toman como referencia para otras subidas.

Lo correcto es aplicar el margen de beneficio (y luego veremos qué porcentaje pudiera ser razonable o normal) sobre los recursos propios. Sobre los recursos que el concesionario pone, que es lo que re- 
almente expone, arriesga, o se priva de tener invertido en otro negocio. En el balance contable de la concesión se ve cuáles son los recursos propios y los ajenos (deuda, préstamos bancarios). Los recursos ajenos ya están siendo remunerados a través de los "gastos financieros" que entran a formar parte de los costos de explotación. Lo que hay que retribuir con un margen normal de beneficio son los recursos propios, y a menos que éstos aumenten a lo largo de la vida de la concesión -algo atípico-, los beneficios que las tarifas han de hacer posibles serían (recursos propios) (margen normal convenido) = una cantidad constante. Si se aplica un equis\% sobre los gastos totales como margen de beneficio:

- se propicia la inflación

- se desincentiva la reducción de costes

- se imputa una remuneración de los recursos ajenos por partida doble.

En el ejemplo del Cuadro I, el nivel de la tarifa viene determinado por (a) unos costos de producción de 516.521, más (b) una dotación al fondo de reversión de 12.630, más (c) unos beneficios de 3.600. Las tarifas han de ser suficientes para cubrir un total de (a) + (b) + (c) $=532.751$; si, históricamente, el consumo de agua fue de dos millones de m3 anuales, la tarifa sería de $0.27 €$.

\section{REVISIÓN DE TARIFAS}

En este apartado conviene mencionar, de entrada, varios hechos incontrovertibles:

- el concesionario tiene derecho a la revisión de tarifas; las cláusulas que se lo nieguen son nulas (Art. 116.3 RSCL);

- la revisión no quiere decir "subida"; la revisión no prejuzga el sentido de la variación si es que la hubiere (puede ser al alza o a la baja); tras una exhaustiva revisión, las tarifas pueden seguir inalteradas, o bajar (y si, por alguna razón no conviene que bajen, el "exceso" debiera ir a las arcas del Ayuntamiento);

- la revisión habrá que hacerla con la periodicidad que se estableciera en los pliegos (anual, quinquenal); 
- además, el concesionario tiene derecho a una revisión cuando la reclama argumentando una ruptura del equilibrio de la concesión causada por (a) modificaciones impuestas por el Ayuntamiento o (b) por causas sobrevenidas e imprevisibles.

Lo más probable es que el concesionario se queje y reclame una revisión cuando la ruptura del equilibrio le perjudique y que se calle cuando la ruptura le favorezca. En todo caso, se deben tomar medidas para restablecer el equilibrio en favor de la parte que corresponda, y el Ayuntamiento, haciendo uso de su potestad de "fiscalizar la gestión" puede iniciar una revisión de tarifas para evitar que los beneficios del concesionario se aparten de lo convenido en la adjudicación. Obsérvese que son también nulas las cláusulas por las cuales el Ayuntamiento renunciare a fiscalizar (Art. 116.2, RSCL). De ello se desprende que la motivación del legislador está en que realmente se fiscalice la gestión o vigile; lo demás es dejación de un deber. Y no se fiscaliza porque el Concejal correspondiente asista una o dos veces al año a la reunión del Consejo de Administración de la concesión. Así cae en una trampa y va de tonto útil, porque figurará en el acta como asistente y se da por enterado y aprueba. Su presencia puede ser una torpeza porque será interpretada por una fiscalización cuando no pasa de ser el preludio de una comida pantagruélica.

\section{III.1. Variación en los costes de producción}

Demos por hecho que tendremos que llevar a cabo una revisión de tarifas cada equis tiempo. Habremos de hacerla forzosamente en el contexto del Art. 115.6, teniendo en cuenta la "descomposición de los factores constitutivos de la misma, como base para futuras revisiones". Para ilustrar cómo podríamos llevar a cabo esa tarea, recurrimos de nuevo al Cuadro I.

En la segunda columna del Cuadro I aparece la importancia relativa (Wi) de cada gasto dentro del total. Es decir, $(353928 / 532751=0.66434)$; 20195/532751=0.037907; es decir, los Sueldos, Salarios y S. Social representan el $66.43 \%$ del total de costos de producción; los gastos financieros, el 3.79\%, y así sucesivamente; la columna dos del Cuadro I suma 100\%, salvo si hubiera un margen de error por redondeo. Siendo así, y siguiendo con los datos del ejemplo, supongamos que al final del primer año el concesionario pide una revisión de tarifas, quejándose de cuánto le han subido sus costes.

Con la estructura de costes que el adjudicatario dio al presentarse al concurso y con los índices de precios que el INE publica (www.ine.es) por sectores y por regiones se puede cotejar cuál sería una subida global "nor- 
mal" de los costes de explotación o de producción, comparándola con la media de lo que han subido los distintos factores de producción en su sector y en su región.

Los índices de variación de precios del INE, si no coinciden exactamente con el contenido de cada epígrafe del Cuadro I, sí, al menos, se pueden aproximar tanto que pueden tomarse como el porcentaje de variación experimentado durante el año en cada epígrafe. Esos porcentajes de variación en los precios son los que aparecen en la columna tres del Cuadro I. Para el epígrafe "Otros", al ser un conjunto heterogéneo, se puede emplear el IPC, mientras que para los demás se emplea su respectivo índice. Multiplicando la columna dos por la columna tres se obtiene la columna cuatro, la variación de cada partida de gasto, teniendo en cuenta su importancia relativa dentro del total. Sumando la columna cuatro, se obtiene el porcentaje de variación global $(1.78 \%)$ que puede interpretarse como lo que sería lógico esperar que hubiesen subido las cantidades a recuperar vía tarifas. ¡Cuidado! Insistimos: esto no quiere decir que las tarifas tengan que subir. Como veremos luego, ésa es una condición necesaria, y no suficiente. Ese hecho por sí solo no demuestra que haya que subir las tarifas un $1.78 \%$ o cualquier otro porcentaje, aunque ya veamos que, de hecho, es bastante inferior al IPC del año (3.0\%). El cálculo de la variación, siguiendo la evolución de los factores constitutivos de la tarifa y su importancia relativa, siempre da un porcentaje inferior al IPC porque hay elementos de la suma (amortización, dotación al fondo de reversión y, generalmente, beneficios) que no varían y su aportación al cambio es nula.

El lector habrá observado que, sin decirlo expresamente, lo que hemos hecho ha sido calcular el porcentaje de la variación global (VG) en los costes contemplados en el RSCL Art. 129.3, aplicando una fórmula que se desprende de los datos suministrados por el adjudicatario, y cuyo despliegue formal sería:

\section{“(VG) Variación global $=\mathrm{w}_{1} \mathrm{P}_{1}+\mathrm{w}_{2} \mathrm{P}_{2}+\mathrm{w}_{3} \mathrm{P}_{3}+\ldots$ ”}

equivalente a la suma de la columna cuatro del Cuadro I. Esto evita que los técnicos de la Administración tengan que dar una fórmula de revisión (ellos nunca sabrán más al respecto que el propio empresario), pues el molde de cualquier fórmula prejuzga la manera de producir del que concursa e impide que él saque provecho (ventaja relativa) de cualquier innovación o técnica que posea. Por ejemplo, para la depuración de aguas pueden añadirse productos químicos reactivos, o pueden inyectarse gases; la función de producción es distinta; la composición y aprovechamiento de los lodos resultan- 
tes varía de un proceso a otro. Otro tanto cabe decir de un concesionario de abastecimiento de agua que haga la lectura de contadores visitando y registrando manualmente u otro concesionario que lo haga tele-informáticamente. Es mejor que ellos den la descomposición de sus costos de producción (que de ahí se derivará la fórmula de revisión) en vez de dar una fórmula para todos los concursantes.

Esa fórmula de revisión que surge de los datos aportados por el adjudicatario no tiene nada que ver con las "Formulas-Tipo" publicadas en el B.O.E. para la revisión de precios en las obras. Estas vienen dadas en términos de cemento, siderúrgicos, ligantes, aluminio, cobre, cerámica, madera, energía y mano de obra, con la importancia relativa de cada elemento ya preestablecida según el tipo de obra, y se mencionan explícitamente en el contrato como la fórmula a aplicar en caso de futuribles revisiones.

De igual modo, el Cuadro II ilustra los Costos de Producción del concesionario ABC de recogida de basuras que ascienden a 848520 , su Dotación al Fondo de Reversión que es cero y sus Beneficios, que calculados sobre sus Recursos Propios aportados a la concesión, ascienden a 3000. Las tarifas que se aprueben harían posible que, mediante una buena y ordenada administración, el concesionario ingrese 851520 anuales. La variación global de la tarifa para el período de revisión sería de (0.021193) ó 2.12\%.

\section{Cuadro II}

\section{CONGESIONARIO ABC DE RECOGIDA DE BASURAS}

\begin{tabular}{l|r|r|r|r}
\hline Sueldos, Slarios y S. Social & 666.400 & 0,78260053 & 0,02 & 0,015652 \\
\hline Gastos financieros y bancarios & 35.200 & 0,04133784 & $-0,0085$ & $-0,00035139$ \\
\hline Amortización & 75.000 & 0,08807779 & 0 & 0 \\
\hline Combustible & 33.000 & 0,03875423 & 0,13 & 0,0050375 \\
\hline Concerv y mantenimiento & 21.520 & 0,02527245 & 0,019 & 0,000475 \\
\hline Seguros, Alquileres y otros & 17.400 & 0,02043405 & 0,019 & 0,00038 \\
\hline \multicolumn{5}{|c|}{} \\
\hline (a) Total Costos Producción & 848.520 & & & \\
\hline (b) Dotación Fondo Reversión & 0 & & & \\
\hline (c) Beneficio/recursos Propios & 3.000 & 0,00352311 & 0 & $\mathbf{0 , 0 2 1 1 9 3 1 1}$ \\
\hline Total Cf. RSCL Art. 129.3 & $\mathbf{8 5 1 . 5 2 0}$ & $\mathbf{1}$ & & $\mathbf{0}$ \\
\hline
\end{tabular}


Para ilustrar la importancia, y a la vez la gran sabiduría, que encierra el Art. 115.6 del RSCL al exigir que se dé la "descomposición (o desglose) de sus factores constitutivos, como base para futuras revisiones", sigamos con el concesionario $\mathrm{ABC}$ de recogida de basuras y su demanda de revisión de tarifas.

El concesionario no es una ONG; es un empresario movido por el ánimo de lucro, con autonomía para introducir en su sistema de producción las mejoras que surjan; por su parte, el Ayuntamiento, también desea que se innove, y propicia o, al menos, no entorpece, que dichas mejoras se implanten. Así, a los dos años de la adjudicación, el concesionario sustituyó los camiones de recogida de basuras, cada uno de los cuales necesitaba tres operarios (el conductor, más dos operarios que iban siempre subidos en el estribo de atrás y que en cada parada acercaban los contenedores para su descarga por la parte trasera del camión y, corriendo, volvían a dejarlos junto al bordillo) por otros camiones más modernos, manejados por un solo operario (el conductor, quien, desde la cabina y mediante palancas, coge los contenedores con unos brazos hidráulicos, telescópicos, los descarga por el costado del camión, y los vuelve a depositar en su sitio). En resumen, la partida de costos de personal y cargas sociales puede haberse reducido a la tercera parte (comparada con la estructura de costes que el concursante dio cuando se presentó y se le adjudicó la concesión). Al atender la demanda de revisión de tarifas, el Ayuntamiento, conocedor de que ha cambiado el modelo de camión y lo que eso conlleva, actualiza la importancia relativa de cada factor constitutivo de los costes, y sigue el mismo procedimiento para calcular la variación que ya se siguió en el Cuadro I. Pero, si al cabo de dos años, el concesionario modificó su sistema de producción (algo encomiable y que no se le puede impedir), su estructura de costos ha variado, al necesitar sólo un operario por camión. Ello se refleja en el Cuadro IIa donde vemos que los Costos de Producción son ahora 456520 y, al ser el resto igual, los tres ingredientes a cubrir por las tarifas ascienden a 459520 , frente a los 851520 que se tuvieron en cuenta para la determinación del nivel inicial de tarifas. 


\section{Cuadro IIa}

\section{CONCESIONARIO ABC DE RECOGIDA DE BASURAS}

\begin{tabular}{l|r|r|r|r}
\hline Sueldos, Salarios y S. Social & 274.400 & 0,59714485 & 0,02 & 0,011942 \\
\hline Gastos financieros y bancarios & 35.200 & 0,07660167 & $-0,0085$ & $-0,0006511$ \\
\hline Amortización & 75.000 & 0,16321379 & 0 & 0 \\
\hline Combustible & 33.000 & 0,07181407 & 0,13 & 0,009334 \\
\hline Conservación y mantenimiento & 21.520 & 0,04678795 & 0,019 & 0,00088901 \\
\hline Seguros, Alquileres y Otros & 17.400 & 0,0378656 & 0,019 & 0,00071953 \\
\hline
\end{tabular}

\begin{tabular}{l|r|r|r|r}
\hline (a) Total Costos Producción & 456.520 & & & \\
\hline (b) Dotación Fondo Reversión & 0 & & & \\
\hline (c) Beneficios/Recur Propios & 3.000 & 0,00652855 & 0 & 0 \\
\hline Total Cf. RSCL Art $\mathbf{1 2 9 . 3}$ & $\mathbf{4 5 9 . 5 2 0}$ & $\mathbf{0 , 9 9 9 9 5 6 4 8}$ & & $\mathbf{0 , 0 2 2 2 3 3 4 4}$ \\
\hline
\end{tabular}

La conclusión inmediata es que, a pesar de que las partidas que forman los costes de producción hayan subido en la economía en general un $2.22 \%$ y, por tanto, es lógico suponer que igualmente le hayan subido al concesionario, no procede una subida de tarifas, porque debido al cambio en la estructura de sus costes, está obteniendo unos beneficios muy superiores a aquéllos en base a los cuales se le adjudicó la concesión. Para situaciones de este tipo, se podría haber estipulado en los pliegos del concurso que si los beneficios superan en más de equis puntos porcentuales aquéllos en base a los cuales se adjudicó la concesión, la diferencia se repartirá a partes iguales, o en cualquier otra proporción, entre el Ayuntamiento y el adjudicatario, o que el adjudicatario hará las obras adicionales que se le diga, para "compartir" el beneficio "excesivo". A pesar de lo dicho, véase en el Apéndice A cómo un Ayuntamiento (el de Tres Cantos, Madrid) trató un caso análogo.

Sin embargo, el concesionario persistirá argumentando que los sueldos de su personal han subido, al igual que el resto de sus costos de producción; si en la economía en general han subido, y para cualquier otro empresario han subido, ¿cómo no le van a subir a él? ¿qué más tiene que demostrar -preguntará- para que le suban las tarifas?

Obsérvese también otro detalle importante de los Cuadros anteriores: la partida de amortización. 
Hay quienes dicen que, en el proceso de calcular la variación de tarifas, no hay que tener en cuenta la amortización. Esa afirmación no perjudicará nunca al concesionario, y tal vez le favorezca; es un atajo, que pudiera no ser válido, aunque sea cómodo. Si el concesionario ha escogido un sistema de amortización constante, cada año amortizará la misma cantidad; no habrá, por tanto, variación de un año para otro; es decir, el porcentaje de variación será cero, como ocurre en los Cuadros, y al multiplicarlo por la importancia relativa de la partida de amortización dentro de los gastos totales, se elimina. Es como si no se tuviera en cuenta. Ahora bien, si el concesionario aplica una amortización acelerada, la cuantía de la amortización será siempre menor en un año dado que en el año anterior; es decir, la variación porcentual de un año para otro será negativa y habrá que tomarla en cuenta porque, en ese caso, su contribución a la variación global será negativa, y reduce algo el porcentaje de variación de los costos de producción.

Puede, además, ocurrir que el concesionario, acogiéndose a medidas fiscales, esté amortizando cantidades mayores a las que objetivamente equivaldrían a una amortización que tuviera en cuenta el desgaste de los equipos y la obsolescencia. A veces el Gobierno quiere con estas medidas incentivar la inversión o propiciar la substitución e innovación de equipos para que las empresas sean más competitivas. Por ejemplo, los equipos incorporados a la concesión bajo la modalidad de leasing -o arrendamiento financiero con opción a compra- pueden amortizarse, acogiéndose a las disposiciones vigentes, al doble de lo que es su coeficiente normal. Y ello es perfectamente legal a la hora de pagar impuestos. Ni la AEAT ni ningún auditor pondrá pega alguna; es, de hecho, un indicio de que el empresario es avispado y sabe cómo pagar menos impuestos. Pero cabe preguntarse si ello debiera ser así a la hora de calcular los costes reales de producir el bien o el servicio (que son los que han de ser cubiertos por la tarifas).

Es pragmático suponer, a menos que el caso concreto aconseje lo contrario, que la diferencia en el porcentaje de variación de los costes globales, si se ignora o si se toma en cuenta la partida de amortización, no es muy importante, pero a sabiendas de que no tomar en cuenta la amortización en el proceso de calcular la variación de las tarifas, jamás perjudica al concesionario y sí puede favorecerle, si se excluye del cómputo global un ingrediente con signo negativo. Además, aceptarle al concesionario una partida de amortización que puede ser correcta y admitida a efectos de pagar impuestos, pero que exagera los costes reales de producción, infla la base inicial sobre la cual se calculan posteriormente las variaciones. Por tanto, aquello de no tener en cuenta la amortización, por sistema, simplifica tal vez en exceso. 
La "amortización" de la que estamos hablando en este apartado se contabiliza como un costo de producción. Se calcula para que recoja el deterioro, desgaste, obsolescencia de los activos fijos, y tiene por objeto acumular suficientes recursos como para reponer o sustituir el bien. Se la suele llamar amortización material o técnica. Su objetivo es acumular fondos para la reposición de los equipos, y puede llevarse a cabo varias veces durante el plazo de vida de la concesión. Es un gasto de explotación o de producción que siempre se debe contabilizar; pero no se paga a nadie de fuera; esos fondos se mantienen dentro de la empresa. La partida de amortización forma parte de los gastos, reduce los beneficios y, por tanto, los impuestos; pero, a la vez, al ser un gasto interno, sin salida de fondos, aumenta el capital circulante con el que el concesionario se desenvuelve. Por eso carece de validez el argumento que mantiene, que al sustituir los equipos viejos, los modernos/nuevos costarán más que la amortización acumulada para reponerlos. Ese argumento ignora que el dinero que se ha ido contabilizando como gasto de amortización y se ha mantenido rindiendo dentro de la empresa ha permitido que, como mínimo, el concesionario haya tenido que pedir menos dinero prestado y, por lo tanto, la amortización acumulada ha rendido, por lo menos, tanto como costaba el crédito que ha sustituido o que ha permitido reducir. (Aparte de que el mayor costo de los equipos nuevos sea debido a mejor calidad, mejores prestaciones, etc.)

Para concluir este apartado, se puede afirmar que es preferible no apartarse de las normas. Estas estipulan que las tarifas se darán "con descomposición de sus factores constitutivos, como base de futuras revisiones”. Así lo ha de entender el que concurse, al decirle en los pliegos que la concesión se rige por el RSCL y al pedirle que desglose sus costes de producción. La fórmula de revisión de tarifas se desprende de los datos que cada concursante se asigna a sí mismo en función de su manera de producir. El Ayuntamiento no prejuzga cuál es el mejor proceso productivo dando él una fórmula de revisión y tampoco impide o dificulta que cada concursante innove en función de su experiencia o de sus conocimientos; más bien al contrario, no dando una fórmula de revisión de tarifas, propicia que cada cual produzca como mejor lo sepa hacer. Por regla general, el procedimiento de cálculo en base a la variación de los factores constitutivos (variación en su costo y variación en su importancia relativa) dará una cifra de variación global bastante inferior al IPC. Y, aunque parezca muy laborioso, no lo es.

Cuidado, de nuevo: hasta ahora sólo se ha hablado de cambios en los costos de explotación o de producción, que son sólo uno de los tres ingredientes que han de ser cubiertos por las tarifas. También hay que ver qué ocurre en 
los otros dos ingredientes: dotación al fondo de reversión, y margen normal de beneficio industrial. $\mathrm{Y}$, aunque todo ello subiera de un año para otro, ello no demuestra que las tarifas deban subir, porque aún no sabemos qué ha ocurrido, simultáneamente, con los ingresos (equilibrio). Sin embargo, para acabar formalmente este apartado, sigamos con los dos ingredientes pendientes:

\section{III.2. Dotación al Fondo de Reversión}

Esta partida, generalmente, será una cantidad fija a lo largo de la vida de la concesión, y no variará de un año para otro, con lo cual su impacto en la revisión es nulo. Pero puede que sí varíe y que así figure en el plan económicofinanciero en función de cuándo se realizan las inversiones o se paga el canon que hay que recuperar como "costes de establecimiento del servicio". Siendo así, habrá que añadir otro sumando más a la expresión anterior que será la ponderación relativa de la dotación al fondo de reversión multiplicada por su variación.

\section{III.3. Margen normal de beneficio}

Si en la adjudicación se le aprobó al concesionario equis puntos porcentuales por encima del rendimiento de la deuda pública a diez años, el porcentaje puede variar de un año a otro. Para agilizar la revisión puede establecerse que este componente no se revisará más que quinquenalmente, o se revisará sólo si su desviación supera en tres-cuatro puntos al índice de referencia. Al ser un porcentaje que se aplica sobre los Recursos Propios, y éstos no suelen variar a lo largo de la vida de la concesión, su impacto en la revisión de tarifas es mínimo.

Supongamos que se ha llevado a cabo el cálculo y que las partes están de acuerdo con él (con el procedimiento, que siendo una cuestión mecánica-aritmética no ofrecería problemas; con índices usados sacados del INE o de otras fuentes, que pueden originar discrepancias menores, y con la cifra resultante). ¿Equivale esto a decir que las tarifas han de ser variadas en el porcentaje de variación global que resulte del cálculo? No necesariamente. Vamos a apoyarnos en una analogía que puede visualizarse fácilmente. Sea una balanza: en el platillo de la derecha "pesamos" todos los ingredientes que han de ser cubiertos por la tarifa (costes de explotación, dotación al fondo de reversión y margen de beneficio), en el platillo de la izquierda "pesamos" los ingresos. El fiel de la balanza es el equilibrio. Algunos costos de explotación suben de un año para otro; otros bajan, su importancia relativa puede variar. Aunque sea cierto que todos los costos suben y que, dada su importancia relativa, todo el 
peso del platillo de la derecha aumente ¿qué pasa simultáneamente, en el platillo de la izquierda? Puede que el fiel de la balanza (equilibrio) siga estando a favor del concesionario. La elasticidad de la demanda o los "rendimientos de la demanda de utilización" (Art. 233.1d TRLCAP) pueden haber provocado que los ingresos por ventas sean superiores a los previstos. Aun cuando fuese cierto que el fiel de la balanza se inclina hacia el platillo de la derecha (que no existe equilibrio, y que el desequilibrio perjudica al concesionario) habría que ver si se ha llevado una buena y ordenada administración. Recordemos el Art. 129.3 RSCL: En todo caso, la retribución prevista para el concesionario deberá ser calculada de modo que permita, mediante una buena y ordenada administración ...

\section{UNA BUENA Y ORDENADA ADMINISTRACIÓN}

Hay varios cauces para saber, en la práctica, si el concesionario ha llevado una buena y ordenada administración. Gracias a la informática, usando los balances y cuenta de resultados que las empresas presentan en el Registro Mercantil, existen varias publicaciones anuales o en internet que, después de haber agrupado a las empresas por sectores, calculan una serie de ratios de estructura de balances, ratios de gestión, ratios de rentabilidad, dando los valores de tales ratios para la media del sector y para las empresas mejor administradas (valores ideales) de cada sector. Con los datos del balance y cuenta de resultados de nuestro concesionario, se calculan los mismos ratios y se comparan con los del sector o con los mejores del sector o se ve si sus ratios caen dentro de lo normal o dentro del cuartil superior (el 25\% de las mejores empresas) o de cuartil inferior (25\% de las peores). Cualquier desviación sorprendente da pie para profundizar en el análisis. Por ej., ¿por qué el ratio Ventas/ Gastos de personal de nuestro concesionario es tan bajo con relación al del sector? Siendo así, pidamos al concesionario que aporte sus TC1 y TC2 para ver quiénes y cuánto cobran con cargo a la concesión. Tal vez se esté pagando un buen sueldo al futurible yerno o al cuñado -para que tenga una buena jubilación- y que no tienen una misión concreta en la empresa, o se está pagando el sueldo íntegro de un asesor jurídico que le lleva todos los asuntos personales al concesionario.

Como ejemplo de la información pública disponible para calibrar si el concesionario lleva o no una buena y ordenada administración, véanse los Apéndices B y C.

Cabe recalcar que el hecho de que las cuentas del concesionario estén auditadas y sin reparos no demuestra que se lleve una buena y ordenada admi- 
nistración. Los auditores se limitan a cotejar que todas las transacciones de carácter económico en las que la empresa ha sido parte se han registrado correctamente, pero no emiten opinión alguna acerca de si dichas transacciones estaban justificadas (cotejan que se han registrado las nóminas y que se han registrado correctamente, desde el punto de vista contable, pero no se pronuncian acerca de si está justificado o no pagarle un sueldo al futurible yerno o ese sueldo al cuñado). La auditoria contable no es una auditoria de gestión.

Insistimos a modo de resumen y aun a riesgo de parecer repetitivos: el concesionario tiene derecho a la revisión con la periodicidad que se haya establecido en los pliegos o siempre que se rompa el equilibrio de la concesión por modificaciones impuestas por el Ayuntamiento o por causas sobrevenidas e imprevisibles; las cláusulas que establezcan la no revisión de las tarifas son nulas (Art. 116.3 del RSCL); la revisión de tarifas no prejuzga el sentido de su variación, si es que la hubiere y que puede ser al alza o a la baja ("en cualquier sentido" según el Art. 127.2, 2ª b del RSCL o "en beneficio de la parte que corresponda” según el Art. 248.2 del TRLCAP), y el demostrar que han subido los costos de producción no demuestra, por sí solo, que haya que subir las tarifas. Es una condición necesaria, pero no suficiente.

a) Sea, primero, el caso de una concesión en cuyos pliegos sólo se dice que se rige por el RSCL, y TRLCAP. En ese caso, las tarifas se varían para hacer posible que se mantenga el equilibrio de la concesión. Y pueden variarse, en cualquier sentido, al alza o a la baja. El incremento en los costes de producción no demuestra que haya que subir las tarifas, porque ¿cómo han evolucionado simultáneamente los ingresos? Bien pudiera ocurrir que el aumento calculado en los costes globales haya sido compensado con creces por aumentos en los ingresos. La pregunta clave es: ¿Qué pasó, a pesar del aumento en los costes, con el equilibrio inicial, aquél cuyos términos fueron considerados para la adjudicación de la concesión? Si aquel equilibrio no se ve perjudicado, no se justifica una subida de tarifas; si aquel equilibrio se ha visto favorecido de manera desproporcionada -una ruptura del equilibrio favorable al concesionario- habría razones para variar las tarifas a la baja.

¿Y si el equilibrio inicial se ha visto perjudicado, en el sentido de que se ha producido una ruptura perjudicial para el concesionario? ¿Hay que subir las tarifas? Depende: 
- Si el equilibrio se ha visto perjudicado por causas sobrevenidas e imprevisibles o por modificaciones impuestas por el Ayuntamiento, habrá que reponer el equilibrio subiendo las tarifas (o de otro modo) ${ }^{2}$ Y no todas las modificaciones exigidas por el Ayuntamiento -aunque impliquen mayores costes globales- desencadenan subidas en las tarifas, porque no se debe ignorar lo que ocurre en los ingresos.

- Si el equilibrio se vio perjudicado por otras causas, habrá que ver si el concesionario llevó "una buena y ordenada administración" porque si no, la subida de tarifas se convertiría en un mecanismo compensatorio para asegurarle unos beneficios, a pesar de una mala gestión.

b) Sea, ahora, el caso de una concesión en cuyos pliegos se estipuló que las tarifas subirían anualmente de acuerdo con el IPC. Esta es una redacción cómoda y desafortunada porque los pliegos forman parte del contrato que el Ayuntamiento firma con el concesionario y habría que ver si la intención de la cláusula era resarcir al concesionario ante una posible ruptura perjudicial del equilibrio mediante subida de tarifas, (siempre y cuando se cumpla la premisa y se den las condiciones necesarias y suficientes para tal subida; es decir, siempre y cuando, previamente, se demuestre que ha habido una desviación perjudicial del equilibrio a pesar de llevar una buena y ordenada administración); se supone que la intención del Ayuntamiento siempre es atenerse a las normas que dice que rigen el contrato y no apartarse de ellas involuntariamente para perjudicarse a sí mismo o perjudicar a los ciudadanos. Es decir, se presupone que cuando el Ayuntamiento da una redacción alternativa o adicional a la que está prevista o implícita en las normas es para no perjudicarse y lo único que busca es un procedimiento más sencillo que se aplicaría cuando que se den las condiciones necesarias y suficientes para que una variación en las tarifas tenga lugar. Si se interpretase de otro modo, cabría decir que no hubo "mutuo entendimiento o mutuo consentimiento" porque no se asentía a algo que las dos partes entendieran de la mis-

\footnotetext{
${ }^{2}$ Obsérvese que se trata de circunstancias sobrevenidas e imprevisibles, que no imprevistas. Si era posible preverlas y el concesionario no las previó en sus cálculos, es problema suyo. Es parte de su riesgo y ventura. Si hay datos o información pública asequible en base a la cual se pueda prever, el hecho de no haber previsto es responsabilidad del concesionario, y no da derecho a que se le suban las tarifas.
} 
ma manera. No hubo meeting of minds o encuentro de las mentes o acuerdo de intenciones, o acuerdo de voluntades. Es decir, aun cuando en los pliegos aparezca la desafortunada expresión "las tarifas se aumentarán, revisarán ... anualmente de acuerdo con el IPC" se da por supuesto que es para restablecer el equilibrio de la concesión (que aparece en el plan económico-financiero propuesto y aprobado) y cabe argumentar que su eficacia surge sólo cuando el equilibrio se perturba (aun llevando una buena y ordenada administración). Y si no, no. Las tarifas subirían, según y como. Para responder, hay que ver qué plan económico-financiero presentó el concursante. Este punto se verá más tarde.

En resumen, el aumento de los costes no justifica un aumento en las tarifas (porque hay que ver qué ocurre con los ingresos); el aumento de las tarifas no es un mecanismo compensatorio para asegurar unos beneficios; el hecho concurrente de que se haya roto el equilibrio tampoco implica que automáticamente hayan de subir las tarifas, puesto que tiene que darse la premisa de una buena y ordenada administración o circunstancias sobrevenidas e imprevisibles; el automatismo en la revisión al alza de las tarifas por el mero aumento en los costes, es una falacia. También puede ocurrir que la variación global en los costes sea negativa. Ese hecho, por sí solo, tampoco demuestra que las tarifas tengan que descender. También conviene olvidarse para siempre de aquella desafortunada redacción en la que se decía que las tarifas "se incrementarán anualmente según el IPC”, porque es una estipulación desequilibrada y anulable, aunque lo más probable es que el IPC suba año tras año. Los jueces decretaron que, en las hipotecas, eran nulas las cláusulas que decían que el tipo de interés aplicable subiría de acuerdo con el mibor, euribor, etc. porque no daban cabida a que pudiera bajar.

\section{SOBRE EL EQUILIBRIO}

La palabra "equilibrio" ha salido a relucir repetidamente en esta exposición. Ahora, se intentará desterrar para siempre la expresión "equilibrio económico-financiero". El RSCL Art.127.2, 2o dice que el Ayuntamiento deberá "mantener el equilibrio financiero de la concesión" y el TRLCAP, Art.248.1 dice que "el contrato de concesión ... deberá mantener su equilibrio económico en los términos que fueron considerados para la adjudicación". La Ley habla de equilibrio económico y el RSCL habla de equilibrio financiero, puestos antes en cursiva intencionadamente, para resaltar la diferencia. No son, pues, lo mismo, y si en unos pliegos se emplea la expresión "equilibrio económico-fi- 
nanciero", no se arregla nada; sencillamente, se mete la pata, por muy bonita que parezca la expresión. Luego hay quienes dicen -porque alguien tuvo que responder a una consulta- que el equilibrio económico-financiero es un "concepto jurídico indeterminado". No. Es, sencillamente, un error. Lo demás es otra manera de encubrir la ignorancia. Cualquier manual de contabilidad analítica nos dice qué es un equilibrio económico y qué es un equilibrio financiero. Este último es un concepto más amplio y, básicamente, se distingue del anterior en que incluye la posibilidad de ajustes estrictamente financieros tales como: ampliaciones de capital, (des)inversiones financieras, una política de reparto de dividendos, etc.

Un concepto jurídico indeterminado pudiera ser "con nocturnidad y alevosía" porque la nocturnidad es variable y subjetiva. Pero cuando algo es el resultado de determinadas operaciones aritméticas, sumando y restando partidas del balance, no es un concepto indeterminado. El resultado de las operaciones puede variar de un caso a otro, pero el encadenamiento de operaciones que hay que hacer, el concepto, no. Para disipar esta nebulosa, basta comparar el Esquema A con el Esquema B, siguientes. El primero recoge los flujos económicos de la empresa: a partir de los ingresos por ventas, corregidos por devoluciones, descuentos, consumos propios, etc. se llega al margen bruto sobre las ventas, con cargo al cual se registran unos gastos internos (llamados así porque, aunque se contabilizan como gastos a efectos fiscales, no se pagan a nadie fuera de la empresa), unos gastos externos (que sí se abonan a terceros), ... El encadenamiento de operaciones indicadas en el Esquema A se explica por sí solo. El orden en que se suman y restan partidas busca ir estableciendo determinados saldos, útiles para otros fines (para la negociación colectiva, por ejemplo). El resultado aritmético del punto 8 del Esquema A es el resultado económico y su signo, positivo o negativo, es clave para la interpretación del devenir de la empresa. Si da cero, se dirá que la empresa está en equilibrio económico, pero, antes, la empresa ha financiado sus inversiones, sus necesidades operativas de fondos, la variación de activos y pasivos circulantes, todo lo cual le permite crecer, seguir siendo competitiva y mantener su segmento de mercado. Todas las operaciones indicadas en el Esquema A se refieren a epígrafes contables que tienen que ver con las actividades económicas de la empresa.

En cambio, en el Esquema B, todas las operaciones indicadas tienen que ver con acontecimientos estrictamente financieros. El punto 5 del Esquema $\mathrm{B}$ es igual al punto 8 del Esquema A, más el saldo financiero, siendo éste un conjunto de ajustes entre los cuales el más relevante en el ámbito de la concesión tal vez sea el reparto de dividendos. El resultado aritmético del punto 6 del Es- 
quema B nos dirá cuál es el saldo financiero: si cero, equilibrio; si positivo, superávit. Se ve que el equilibrio financiero incluye al equilibrio económico, y algo más. Se ve que no es lo mismo el equilibrio económico que el equilibrio financiero, y que, por tanto, la expresión "equilibrio económico-financiero" es una torpeza, un error grandilocuente ${ }^{3}$.

En los pliegos sería preferible usar "equilibrio económico" como hace el TRLCAP, porque el "equilibrio financiero" implica aceptar una política de dividendos, al menos declarados, aunque no necesariamente distribuidos; su magnitud, sin embargo, se puede limitar porque es información que se puede exigir que aparezca en el plan económico-financiero.

\footnotetext{
${ }^{3}$ Para consolar a los que se hayan equivocado, hay que señalar que sí existe el plan económico-financiero, y de ahí tal vez venga la confusión
} 


\section{ESQUEMA DE FLUJOS (A) ENFOQUE ECONÓMICO}

1. Ventas

\pm (ajuste: devoluciones, descuentos y otros productos de explotación

2. Ventas netas totales

- consumos aplicados a las ventas

3. Margen bruto sobre ventas netas

- gastos internos (amortización y fondo reversión)

- Gastos externos (seguros, transporte, etc)

- Impuestos y tasas

4. $=$ Valor añadido vendido

- Salarios aplicados a ventas

- Cargas sociales

+ Subvención de explotación

5. $=$ Excedente Bruto de Explotación (EBE)

O Fondos Generados por las operaciones (FGO)

- Variación de stocks

6. $=$ Excedente sobre operaciones

- Variación de créditos a clientes (incluidos efectos descontados y no vencidos)

+ Variación deudas a proveedores

+ Variación otros decalajes de pagos

7. = Excedente de Tesorería de Explotación (ETE)

o Caja Generada por las operaciones (CGO)

- Inversiones (materiales e inmateriales)

\pm Variación deudas a acreedores por inmovilizado

8. = Disponible después de financiación interna del crecimiento empresa (DAFIC) 


\section{ESQUEMA DE FLUJOS (B) ENFOQUE FINANCIERO}

\section{Flujos patrimoniales}

(Emisión de acciones, enajenación inversiones financieras, inversiones financieras, nuevos préstamos...)

\section{2. + Flujos financieros}

Gastos financieros (entre ellos, leasing), efectos descontados y no vencidos

\section{3. $=$ Saldo bancario}

- Impuestos sobre beneficios

4. $=$ Saldo Financiero

5. $=$ Saldo de gestión $=$ DAFIC + Saldo financiero

- Dividendos

+ Incremento capital propio

+ Dotación para inversión

+ Inversiones financieras

+ Ingresos por enajenación activos

+ Ingresos financieros

+ ingresos excepcionales

6. $=$ Variación de la liquidez 
Los economistas emplean la expresión "elasticidad de la demanda" para decirnos cómo se comportan los ingresos ante cambios en los precios del servicio, cambios en el precio de las alternativas, cambios en la renta de los usuarios, cambios en sus gustos, etc. Es lo mismo que quiere decir el TRLCAP, Art. 233.1d con las palabras "Deberá ser objeto de consideración específica ... los rendimientos de la demanda de utilización de la obra". En los casos en que la elasticidad de la demanda es mayor que uno, los ingresos suben, aunque los precios del servicio bajen. Y bien pudiera ocurrir que los ingresos del concesionario hayan subido y compensado con creces la subida de los costes (luego no ha habido ninguna ruptura desfavorable en ningún equilibrio), por variación en los precios del servicio, por variación en la renta del consumidor, por variación en sus gustos o por otros factores. Es decir, la ruptura del equilibrio no se demuestra aludiendo a la cuenta de resultados o al nivel de costes del año anterior y reclamando una subida de las tarifas porque han subido los costes con relación al año anterior. Acceder a ello equivale a garantizar unos beneficios (y no olvidemos que el concesionario va a su riesgo y ventura). Las tarifas han de ser suficientes para que pueda obtener un beneficio, dada una buena y ordenada administración. Pero no hay que subirlas para que obtenga un beneficio. Antes, como condición necesaria y no suficiente, habrá que demostrar que se ha producido una ruptura en el equilibrio que se consideró al otorgar la concesión; luego, que esa ruptura desfavorable no es debida a una mala gestión, sino a factores o circunstancias sobrevenidas e imprevisibles porque si eran factores o circunstancias susceptibles de haber sido previstos -aunque el concesionario no los previera- tampoco justifican que se suban las tarifas para compensar la falta de previsión del concesionario.

Si al concesionario se le impone una modificación en el servicio que conlleva mayores gastos, es preferible esperar al ejercicio siguiente para ver el impacto de tal medida sobre los ingresos, en vez de compensarle en la negociación con una subida en las tarifas, o de otro modo. ${ }^{4}$

\footnotetext{
${ }^{4}$ Varios ministros de Obras Públicas cayeron en esa trampa: pidieron a las autopistas que no subieran el peaje para contener la inflación, y éstas exigieron una compensación porque tenían derecho a subirlo anualmente en función del IPC. En la negociación, se les compensó ampliando el objeto social y/o ampliando el plazo de la concesión 20-25 años. Posteriormente se vio que, al no subir el peaje, la utilización de la autopista aumentó y el aumento de los ingresos compensó con creces la no subida del peaje. Aparte de no subir el peaje, pudieron intervenir otros factores tales como el establecimiento de parques de ocio -Port Aventura, Terra Mítica-, aumento de la renta, aumento de turistas que vienen con sus coches a la costa, etc. Pero todo ello demuestra que el impacto de la medida se tiene que medir a posteriori y no compensarlo de antemano. En este caso, habría que preguntarse, además, si la compensación fue equilibrada (por no subir el peaje durante un año, se amplía la concesión 20 años).
} 


\section{PLAN ECONÓMICO-FINANCIERO}

Un plan económico-financiero (ver al respecto TRLCAP, Art. 233.1d) de un proyecto o de una empresa incluye como mínimo los siguientes apartados:

a) El origen y aplicación de fondos. En el origen de los fondos dirá el concursante cuánto son recursos propios, cuánto son recursos ajenos (es decir, deuda y su estructura). El Ayuntamiento puede -y debiera- exigir a los concursantes un porcentaje mínimo de recursos propios. El desglose del origen de los fondos equivale al "pasivo" de un balance. La aplicación de fondos explica a qué se van a dedicar los recursos (caja, bancos, bienes fungibles, maquinaria, inmuebles, etc.) y equivale al lado "activo" del balance. Lógicamente, el origen y la aplicación de fondos coinciden. Su cuantía, clasificada según su procedencia, debe coincidir con su cuantía, clasificada según su destino; por eso justamente se llama "balance". Es necesario que en el plan se diga qué parte (cuantía) son recursos propios, porque ésos son los que el concesionario pone en la concesión. Esos son los que expone, arriesga, y hay que hacer posible que sobre ellos obtenga un "margen normal de beneficio industrial".

b) Las previsiones económicas y evolución de ciertas magnitudes, tales como las ventas, los costes (de personal, financieros, impuestos, etc.) y sus respectivas elasticidades.

c) La sensibilidad de los beneficios ante distintos escenarios en los que se responde a preguntas tales como "¿qué ocurriría con los beneficios si los costes financieros/de personal/etc. en vez de crecer, por ej., al $2.5 \%$ crecieran al $3.5 \%$ ?".

d) La tasa interna de rendimiento (TIR) del proyecto. Esa TIR es un tipo de interés que se emplea para descontar los beneficios de cada año futuro, actualizarlos al presente -homogeneizarlos- y poderlos sumar, acumulando tantos años como hagan falta hasta recuperar la totalidad de la inversión realizada en el proyecto. Como en este cálculo puede variar el número de años y también el tipo de interés, se suele fijar uno u otro, de tal forma que se pueda responder a la pregunta "con una TIR dada de equis \% ¿cuántos años se tarda en recuperar la inversión?" o "teniendo en cuenta los beneficios de los próximos equis años, ¿qué tipo de interés hace falta para recuperar la inversión?" 
Lo anterior es el contenido básico de un plan económico-financiero, y los dos adjetivos se justifican porque el plan indica el origen de los fondos (que, junto con el apartado d) anterior, en que se calcula el TIR, es la parte financiera del plan) y el resto son aspectos económicos. En las grandes concesiones, este estudio es parte ineludible de una Memoria y en él se ve tanto el equilibrio económico como el financiero a lo largo de los años que abarca el plan. En el caso de concesiones menores, si no se pide un plan económico-financiero, sí debe pedirse la cuantía de recursos propios, porque a ellos se les aplicará como retribución el margen normal de beneficio industrial.

En el renglón "Ingresos por ventas" del plan económico-financiero se desglosan los ingresos debidos al mero crecimiento en volumen de la demanda y los debidos a la subida de las tarifas (precios), si es que esta posibilidad la contempla el concesionario en sus cálculos. Los beneficios previstos para cada año a lo largo de la vida de la concesión se actualizan para comparar su valor con el desembolso o inversión inicial y ver así qué tarifa es la que haría que el proyecto fuese rentable o rindiera un mínimo deseado.

\section{FISCALIZAR LA GESTIÓN}

Las normas establecen un insospechado equilibrio entre las potestades que se reserva el Ayuntamiento y las obligaciones que contrae. El Ayuntamiento se reserva la potestad (RSCL, Art. 127) de ordenar discrecionalmente modificaciones en la calidad, cantidad, tiempo, frecuencia ... de las prestaciones en que consista el servicio, alterar las tarifas y (Art. 127.1,2a ) "Fiscalizar la gestión del concesionario, a cuyo efecto podrá inspeccionar el servicio, sus obras, instalaciones y locales y la documentación relacionada con el objeto de la concesión, y dictar las órdenes para mantener o restablecer la debida prestación". En parecidos términos se expresa la Ley TRLCAP, Art. 249.1 b y f.

Los manuales de gestión de empresas (management en inglés) -ver por ej. el prestigioso de Ernest Dale, Management: Theory and Practice, McGraw-Hillexplican que las funciones del gerente o del gestor (manager) incluyen:

a) planificar: establecer objetivos a corto/medio/largo plazo en función de determinados medios para alcanzarlos;

b) controlar: cotejar que los objetivos se alcanzan, corregir desviaciones, controlar gastos; 
c) contratar personal: definir las tareas de sus puestos y estimularlos para que cada cual rinda gustosamente al máximo de lo que es capaz;

d) prever e innovar: nuevos productos, nuevos procesos, otros usos para los mismos productos, desinvertir, etc. para mantener su ventaja competitiva;

e) administrar y recompensar: establecer una organización en departamentos y una estructura de salarios correctas;

f) representar a la empresa ante la sociedad.

En base a ello, fiscalizar la gestión abarca todas y cada una de dichas funciones; y si el Ayuntamiento se reserva la potestad de fiscalizar la gestión, se reserva la potestad de exigir cuentas en cada uno de esos aspectos de la gestión; otra cosa es que lo haga, o que piense que lo ha hecho. Como se ve, "fiscalizar la gestión" está muy lejos de quedarse en una mera auditoria contable.

Para fiscalizar la gestión puede el Ayuntamiento inspeccionar locales, obras, etc. y examinar la documentación relacionada con el objeto de la concesión; es decir, la contabilidad de la concesión como unidad productiva, autónoma e independiente de cualesquiera otras concesiones lleve la empresa. Así se podrá evitar, por ej., que el concesionario contabilice como gasto con cargo a la concesión A compras de productos que usa en las concesiones B, C ..., o servicios de transportes, o asesorías etc. que se emplean en sus otras concesiones. De todos modos, obsérvese que si así lo hiciera, en el momento de compararle con otras empresas de su sector para ver si lleva una buena y ordenada administración, ipso facto aparecería que su gestión es mala y que sus mayores gastos no han de ser cubiertos con subidas en las tarifas (suponiendo, claro está, que los demás del mismo sector no están haciendo las cosas mal como él., lo cual es mucho suponer porque los Ayuntamientos han hecho históricamente dejación de su potestad de fiscalizar la gestión).

Como contrapartida a esas potestades que se reserva la Administración, deberá (RSCL, Art. 127.2.2ํㅜ).

"mantener el equilibrio financiero de la concesión" y si en el ejercicio de alguna de aquellas potestades ha perturbado dicho equilibrio "a) compensará económicamente al concesionario por razón de las modificaciones que le ordenare introducir en el servicio y que incrementaren los costos o disminuyeren la retribución, y 
b) revisará las tarifas y subvención cuando, aun sin mediar modificaciones en el servicio, circunstancias sobrevenidas e imprevisibles determinaren, en cualquier sentido, la ruptura de la economía de la concesión"

Las modificaciones impuestas, por el mero hecho de que aumenten los costos o disminuyan los beneficios con respecto al año anterior, no dan derecho per se a que suban las tarifas como compensación; para que ese derecho nazca debe haberse perturbado el equilibrio que fue considerado para la adjudicación.

La redacción está bien clara: el Ayuntamiento deberá mantener el equilibrio ...para lo cual compensará; pero no deberá compensar -aunque imponga modificaciones- si el equilibrio se mantiene.

Ya se dijo que la revisión de las tarifas no prejuzga el sentido de su variación, si la hubiese. La variación puede ser en cualquier sentido (pueden subir o bajar); es decir, si se produjese una desviación excesivamente favorable para el concesionario, apartándose del equilibrio cuyos términos fueron considerados para la adjudicación, la conclusión de la revisión de tarifas puede ser un no-aumento o una bajada (o un "compartir" los beneficios excesivos). Circunstancias sobrevenidas pueden ser aumentos en la población, en su renta... aumentos en el tráfico que provoquen un aumento desmesurado en los ingresos del concesionario y que justificarían una revisión a la baja de las tarifas. Pero, como eso de bajar las tarifas es algo inaudito, y hasta inconveniente, se puede estipular en los pliegos que si los beneficios de la concesión superan en equis puntos porcentuales a los contemplados en el plan económico-financiero, el exceso se repartirá en tal proporción entre Ayuntamiento y concesionario o se destinará a las inversiones que se le digan.

Por eso, no hay que ser alérgico a las revisiones de las tarifas, con la periodicidad que se hubiera estipulado. Como el Ayuntamiento tiene la potestad de fiscalizar la gestión (iy no puede renunciar a ello!), lo cual incluye estudiar "la documentación relativa al objeto de la concesión", es decir, la contabilidad de la concesión como unidad productiva independiente de cualquier otra, la dificultad está en tener o no los medios para ejercer dicha potestad. Es cuestión de capacidad (tener personal cualificado y con tiempo para ejercer la potestad, o tener los recursos para poder recibir la asistencia externa apropiada).

Al final, el problema suele ser siempre el mismo: no tener las ideas claras y, aun teniéndolas, verse obligado a defender una postura sin el respaldo de la superioridad frente a otro con más medios y más tiempo. 


\section{APÉNDICE A}

El concesionario sustituye motu propio unos camiones de recogida de basura por otros de carga lateral; pide el costo de los nuevos contenedores, y el Ayuntamiento se lo abona.

\section{Se comprarán contenedores para Soto de Viñuelas}

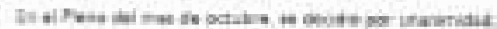

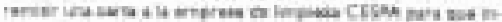

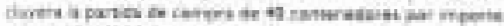



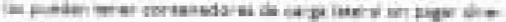
rs astianal

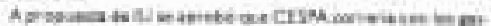

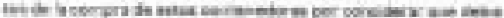

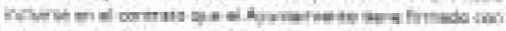
atia norpitis

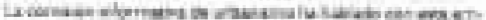

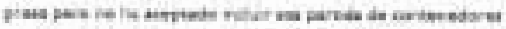

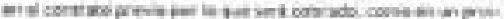

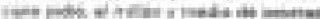

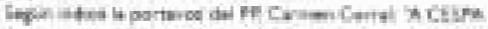

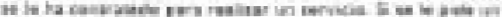

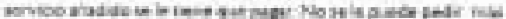

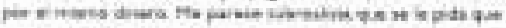

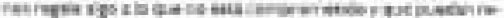

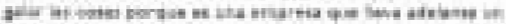



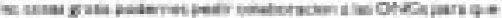

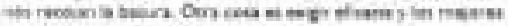

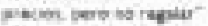

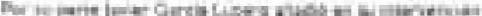
at 7

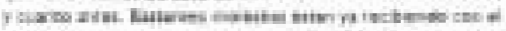

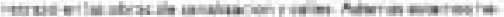

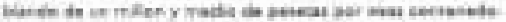

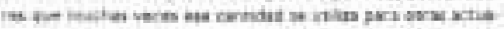

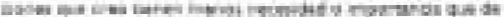

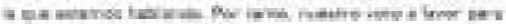
tia se line a evibo la cospra"





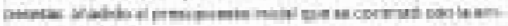
wras cromk

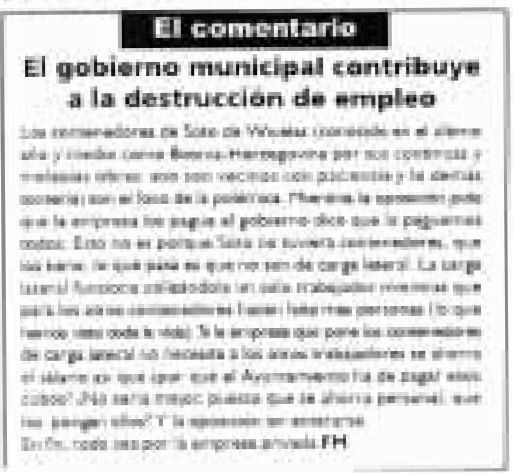




\section{APÉNDICE B}

Lista de sectores en los que típicamente se otorgan concesiones y que figuran específicamente en la publicación.

Ratios de las empresas más rentables, Ed. Gestión 2000, anual

\section{MUESTRA DE CÓDIGOS SIC Y COMPARACIONES DISPONIBLES}

$0782 \quad$ Servicios de jardinería

0783 Servicios ornamentales de arboristería

0849 Obtención de productos forestales

$0851 \quad$ Servicios forestales

1611 Carreteras y calzadas

1623 Alcantarillados, conducciones de aguas

2016 Mataderos avícolas

$2721 \quad$ Edición de revistas

$2731 \quad$ Edición de libros y folletos

4119 Transporte urbano de pasajeros

4141 Transportes de pasajeros en servicios discrecionales

$4151 \quad$ Servicio de transportes escolares

4225 Almacenes generales de depósito

$4784 \quad$ Autopistas, puentes y túneles de peaje

$4939 \quad$ Empresas combinadas de servicios públicos

4941 abastecimiento de aguas

4952 Depuración de aguas residuales

4953 Recogida y tratamiento de basura

$5813 \quad$ Bares y cafeterías

$7261 \quad$ Servicios funerarios

$7331 \quad$ Servicios de reparto de correspondencia y publicidad directa

7341 Servicios de limpieza de ventanas, escaparates

7349 Servicios de limpieza y conservación de edificios

$7379 \quad$ Servicios relacionados con computación

$7932 \quad$ Billares y piscinas pública

8059 Servicios de asistencia médica

8211 Colegios elementales y secundarios 8351 Guarderías 


\section{APÉNDICE C}

- Información estandarizada que KPMG España publica regularmente para 276 sectores.

- Ratios de las empresas más rentables

- Información estandarizada publicada por Dun\&Bradstreet

- Información estandarizada asequible vía internet en www.informa.com

\begin{tabular}{|c|c|c|c|c|c|c|c|c|}
\hline \multirow[b]{2}{*}{ Minero at erpiesas } & \multicolumn{4}{|c|}{ Canndarna tebintwón } & \multicolumn{4}{|c|}{ Captasian ileparzian y dabtainen de aqua } \\
\hline & $\$ 3$ & 7 & 58 & T & 199 & 3 & tos & $\boldsymbol{n}$ \\
\hline Ratios & 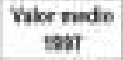 & $\begin{array}{c}\text { Valorited } \\
\text { Im? }\end{array}$ & $\begin{array}{c}\text { Vaforned: } \\
1854\end{array}$ & $\begin{array}{c}\text { Valor ideal } \\
\text { tass }\end{array}$ & $\begin{array}{c}\text { Youer meas } \\
\text { 15s? }\end{array}$ & $\begin{array}{c}\text { Veoridual } \\
\text { twi }\end{array}$ & $\begin{array}{c}\text { Vxarnerha } \\
\text { ISas }\end{array}$ & $\begin{array}{c}\text { Vxier icteai } \\
\text { tsat }\end{array}$ \\
\hline upater & $17 x$ & 19 & 1,10 & 100 & 1.11 & tat & 9,13 & 109 \\
\hline Solentis 3 brp paxo. & 1,00 & un & 1,20 & 109 & 108 & tar & 111 & 1.01 \\
\hline Erotutrets & Q & nin & $\pi \mathbb{R}$ & $39: 91$ & at $\pi$ & 3421 & 4531 & $2 x, 11$ \\
\hline Cxhad de be deati: & 0,88 & 1,00 & 0.89 & as? & 151 & $0,2,2$ & 0.52 & $6,5,5$ \\
\hline  & 2002 & 4,16 & $1,0 \pi$ & 251 & IffE & Q⿻3 & 0.57 & 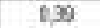 \\
\hline Caitas lranciatue actirs ietan & 0,00 & ast & 0,00 & ato & 1,0 & 002 & all & 605 \\
\hline Batsonen ds xtrap: & $2 \%$ & 343 & 286 & 200 & 14 & an & 0.45 & 0,8 \\
\hline Astacion di xatwo to & $12 . \pi$ & 1433 & 110 & 22.25 & is & 06 & 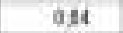 & 0,05 \\
\hline 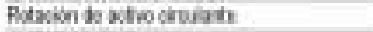 & $2 \pi$ & 19 & $2 \pi$ & 255 & 1.48 & $1, \pi 0$ & 134 & 1,00 \\
\hline Rotrion de thabs & 8,06 & $9 \pi$ & DAB & 9029 & 25.6 & $\pi 5 T$ & 58 & $H, 09$ \\
\hline Awa de ceros dent & 600 & 96 & 600 & Q.90 & 14100 & 14000 & 13611 & 60,00 \\
\hline 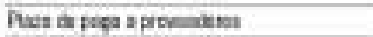 & 11100 & 11456 & 11600 & 11200 & 27160 & tonos. & 3211 & 30400 \\
\hline hropetat & $62 \pi$ & $a 00$. & 3,12 & 000 & 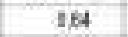 & $1 x$ & $a n$ & 134 \\
\hline  & 0.38 & & $0 \leqslant 0$ & & 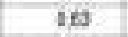 & 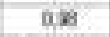 & 028 & 0,15 \\
\hline Plicen notsige prans & $+1,00$ & 901 & 10,00 & 7.83 & wot & 9,00 & 19511 & 3,00 \\
\hline Plos passicios encene & 0,00 & an & 0,00 & 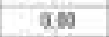 & 17.0e & 5300 & 2513 & st, 00 \\
\hline Ples probutes tenviades & 0,00 & था & 0,000 & 20 & 1,06 & 000 & 186 & 0,000 \\
\hline knda frarctu sdere vertas & 0,05 & 9.12 & $60 \hat{1}$ & and & 200 & 0,01 & ast & 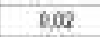 \\
\hline Finda faristea actur iation & 0,18 & aft & 0.28 & as & 108 & an & 160 & 0,00 \\
\hline fartainat etaranca & $6, \pi 6$ & wat & $7 g$ & ats & 160 & 68 & 424 & 3.6 \\
\hline Rurbsitsst thandesa & $\pi, 0$ & Ms: & $15 \pi$ & 9201 & $7 \pi$ & $7 \mathbf{a}$ & 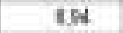 & 1,09 \\
\hline Ypalonesenete tranciens & 200 & 18 & $3 \mathbf{M}$ & 7,45 & $2 B 2$ & $x, 9$ & 23 & 2,15 \\
\hline 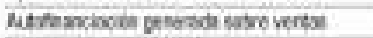 & 0,03 & 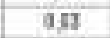 & 0,00 & a.s & 1,13 & 0.21 & 1,17 & 0,9 \\
\hline 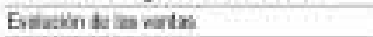 & 1,06 & t.11 & 1,13 & 13 & 1,12 & $t, 34$ & 1,14 & $13 t$ \\
\hline Evataikn du atial & 1,09 & 217 & 1,108 & 1,55 & t11 & 1,06 & 125 & 1,62 \\
\hline 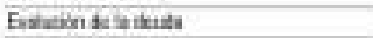 & 1,00 & titi & 1,10 & 1,42 & 112 & 0,8 & 1,14 & 129 \\
\hline  & 13 & 12 & 10 & tas & 131 & 1,74 & 12 & 180 \\
\hline
\end{tabular}


[XC.JM]E-[TTOS

\begin{tabular}{|c|c|c|c|c|c|c|c|c|c|}
\hline $\begin{array}{l}\text { Arson } \\
\text { Sectsriatus }\end{array}$ & C.sumix & Uedan & C. vinis & C. Supativi & Mactusa & C btocar & C separier & Nedure & C Interios \\
\hline \multicolumn{10}{|l|}{ Stucinfroutien } \\
\hline Laqider (mene) & is & 6 & 14 & ta & Q6. & as & $\mathbf{u}$ & At & 11 \\
\hline 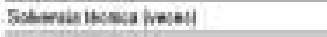 & 14 & 10 & 11 & 4 & 10 & of & 14 & u & 11 \\
\hline 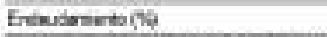 & 881 & 215 & $76 a$ & 23at & 248,1 & 385 & 21 & ini & S121 \\
\hline 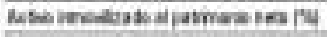 & $\pi T$ & Es & $2 \mathrm{na}$ & 90 & 793 & 1002 & 21 & 43 & 164 \\
\hline Enteudemerto acsto 79 & ess & 28 & 5021 & 224 & 1088 & thes & ist & 1514 & 412 \\
\hline 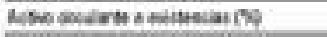 & 312 & 273 & 201 & ins & $2 x=0$ & 4713 & 1328 & 2011 & จบ1 \\
\hline \multicolumn{10}{|l|}{ Bnitured } \\
\hline 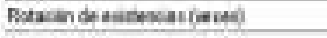 & 158 & 3.1 & 28 & $4+4$ & E.6. & 20 & 121 & 19 & 25 \\
\hline  & $3 t s$ & 136 & $\mathrm{H} 12$ & Bas & $\leqslant 0$ & 1113 & 2.3 & 50 & 1119 \\
\hline Bazande atver (S) & 2002 & 41: & 2721 & 720,0 & $\operatorname{ins} 3$ & 139 & 311 & I11 & int \\
\hline 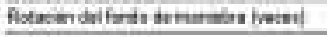 & 116 & 23 & 42 & th: & 18 & $\$ 0$ & 114 & 25 & 7,1 \\
\hline  & 413 & 578 & 183 & $3 \pi$ & $\mathbf{x}, 1$ & De & ni: & 20, & 34 \\
\hline 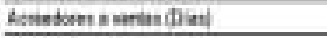 & 84.6 & tist & 2015 & 7.2 & 1203 & $17 \pi$ & 124 & t114 & the \\
\hline \multicolumn{10}{|l|}{ Buntaliad } \\
\hline 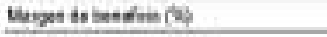 & 31 & 13 & 12 & $\$ .2$. & $1, t$ & 0.0 & 21 & al & 24 \\
\hline 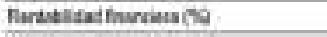 & 413 & 18 & 41 & 487 & 180 & 28 & 439 & 12.1 & +19 \\
\hline 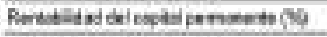 & HI & 11 & II & 264 & 60 & ap & 28,1 & $7 A$ & 28 \\
\hline 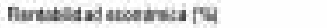 & is & 28 & 14 & a.t & 11 & +13 & 20 & 5 & 41 \\
\hline
\end{tabular}


Consideraciones económicas en las relaciones con los concesionarios

Sectoe tionplo

1589

13 st

1030

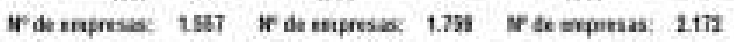

\begin{tabular}{|c|c|c|c|c|c|c|}
\hline Nemias & Vuar en niles & 8 & Vilar ea niles & 5 & Vabe en siles & $\$$ \\
\hline ineverabenstorid & 19.834 & 21,5 & 19.741 & 21 & 11823 & 21,4 \\
\hline  & 5144 & 44 & $4 \$ 74$ & 6.2 & 3591 & 15 \\
\hline Tolu intikitad & 25.43 & 272 & 24617 & 31,3 & $15,4+4$ & 272 \\
\hline Exhve & 4571 & 34 & $3 a s 4$ & 4 & 3004 & 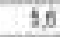 \\
\hline Edanime & 32.95 & 428 & 3058 & 204 & 22561 & 41,2 \\
\hline Eotsneas & 18.993 & 219 & Ireas & 2.5 & 12601 & 229 \\
\hline  & tata & 21 & 1415 & 18 & $12 \pi t$ & 23 \\
\hline 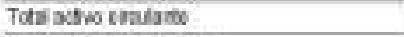 & 6.313 & $n 21$ & 53953 & 0.7 & $n \pi T$ & 72,1 \\
\hline Toed action circalanis & It.4in & 1326 & T2.5ti & 100,1 & 25.191 & 310 \\
\hline Caply suwara & 8594 & 3.4 & 8415 & 10,7 & $70+5$ & $12 . T$ \\
\hline Hownen & MA191 & 132 & 12602 & 16.1 & 1.184 & 155 \\
\hline Pruelatay faz & 274 & 13 & 551 & 0,7 & 2873 & -52 \\
\hline Fondos propice & 7273 & 249 & 21623 & $2 \pi, 5$ & 12500 & $21 \mathrm{~A}$ \\
\hline Painea laropolas & 11415 & 125 & 10.462 & 133 & 1002 & Dis \\
\hline Devdnu on erdidades te credio s conto phace & 5571 & 1,1 & 2599 & 21 & 1508 & 1,6 \\
\hline Aatetures bxtchatit & Aा की & 52,1 & 40425 & 51,5 & 33927 & 50,7 \\
\hline Otoo asrecdeites a censo piage & 4a18 & 44 & 3 as? & 3,3 & 1326 & 24 \\
\hline Tats pasve circiarin & 5.259 & \$2.5 & 86491 & 59,2 & $324 t$ & 45.7 \\
\hline Toed pasino & 91,441 & 5020 & Tasas & 100,1 & 58.191 & 1910 \\
\hline \multicolumn{7}{|l|}{ Cuerta da plidida, ganoncias } \\
\hline inperen noto da la ofre do seposas & 13069 & 5919 & $140: 19$ & प्रa1. & Tेक & $\pi \%$ \\
\hline Detro ngreina da toplatein & 1454 & 11 & 139 & 1,2 & 1002 & 12 \\
\hline Tocd ingesss de explotacian & 132.143 & 50.0. & 111.395 & 160,3 & $11: 40$ & 190 \\
\hline Rorwenurarianthe & 7432 & 563. & 61245 & 550 & 4663 & 53 \\
\hline pastos de savered & 33.293 & 25.2 & 26952 & 26,1 & 21266 & 295 \\
\hline 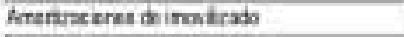 & 2.817 & 22 & 2452 & 2,2 & $1 \pi 1$ & 20 \\
\hline 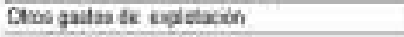 & 4535 & 110 & $13 \pm n$ & $\pi, 7$ & 9562 & 118 \\
\hline Toed gastas de expletacion & 123707 & 852 & $109 \mathrm{~ms}$ & $M$ & 16398 & 37) \\
\hline Betefkieipenifle de equalxien & 8.353 & 48 & 5.679 & S,1 & 1,548 & 22 \\
\hline Resultados trenoevss & 2911 & 22 & 3229 & 2,7 & 2 & 26 \\
\hline  & $t$ & 0,0 & 334 & 0,3 & 286 & 83 \\
\hline Benefikieberido altes de hpatstes & 3.436 & 2,8 & 2.714 & 2,1 & 0 & 10 \\
\hline inpuedas & $-1+13$ & 49 & 261 & $-0,8$ & +2 & $-4, t$ \\
\hline Benefikiehentide del tjacic b aneelor & 2154 & 16 & 1.393 & 1,7 & $\$ 9$ & 4,1 \\
\hline
\end{tabular}


Fatice

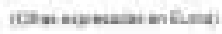

\section{Netaviant}

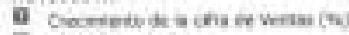

0 Mranar it Actes

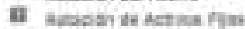

in cremenes del vaiv alasdo fN!

\section{mosuctivibari}

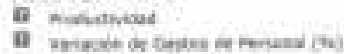

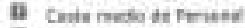

a west Mutes per Crowaba

\section{casn now}

D. cashine

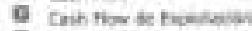

D Enducate of Con nos (S)

\section{ARNTAETIBAB}

Q keriatitat fasonima (W)

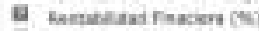

D hiebue fmascorse ith:

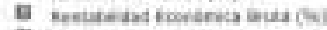



goundanto (Ex fias de cha de vatae)

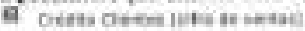

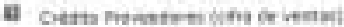

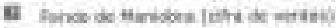

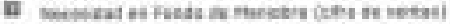

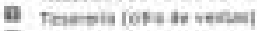

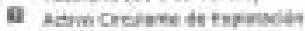

equnawr:

D lanas an hovars

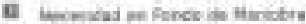

a tevereis

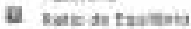

\section{SoLvenas}



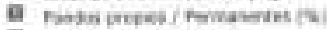

Q coradised to Denekrese



C. hiancomoess (t).

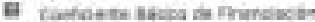

8 cantia de Alus

\section{upuraes}

5. tiqusea Gerina



\begin{tabular}{|c|c|c|}
\hline 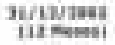 & 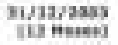 &  \\
\hline ebual & II is & $\omega$ \\
\hline and & un & un \\
\hline 1,14 & 1.13 & 4.31 \\
\hline and & 1789 & \\
\hline tat & 1.31 & , \\
\hline ander & B.at & 13.11 \\
\hline etwatil & $34 \sin 23$ & Intrive \\
\hline in.ted,ax & antat, & , \\
\hline 3.me rast & I actansed & tistava 11 \\
\hline itedersin & i. 4 is $3 \times 6=$ & 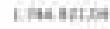 \\
\hline an & 7,14 & 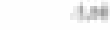 \\
\hline $\tan$ & t.m & 4,is \\
\hline 78.41 & ax: & whin \\
\hline kas & $1, \pi$ & in \\
\hline ins & xis & $a r p e$ \\
\hline 14.11 & 12,11 & mit \\
\hline
\end{tabular}

$a$

int

27

19

it

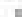

$1 \mathrm{~m}$

และวามง cus nas, at on inan

10

Wostex: insisen: Irrait, es

enging

con $\min$

nis

a.

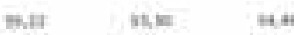

iris nat inat

sai

an

ins

intse

inti

nen

in

itsis

ainis

$n, t$

$1 \mathrm{~ns}$

a, an

ats

s.21

1.94

1.94

Drandes Mases Patrimoniaies Actro

\begin{tabular}{|c|c|c|c|c|c|c|}
\hline  & 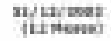 & 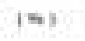 & Museires & $1=1$ & 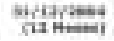 & $1=1$ \\
\hline 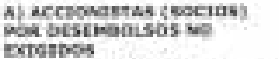 & & & & & & \\
\hline 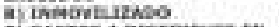 & E.jea.aid.42 & tesacki & com atosel- & tan:asen & gant bie est & -50401 \\
\hline 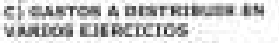 & - 4.014 .47 & |togetsi & A.Ast,ay & |+atarsi & secuta.4s & $(6,2,946)$ \\
\hline 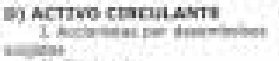 & then & $+4 k, 1001$ & R.64.79aver. & 148.6969 & raskabses & itanes: \\
\hline 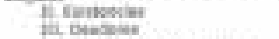 & Masese & limile: & 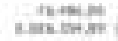 & interesis & $\begin{array}{l}n \sin : 4 \\
\sin 3 i s=62\end{array}$ & hosers \\
\hline 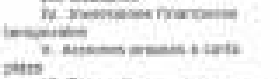 & axurexs & $1+0406$ & sedronst & interses & bens on & jases: \\
\hline Vi. Teverwe & manas! & $1+4, \pi w$ & 1. Harman & $14 \pi, 2101$ & int 70200 & $|\mathrm{pecme}|$ \\
\hline
\end{tabular}


Aiesaitato Antes Impiestes

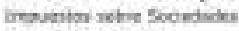

Anesitaten Neto

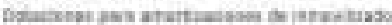

Veriacile de wonatices:

Autufiasaciacien weta

\section{Ratios}

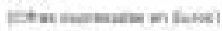

[1s, $7 \mathrm{~s}$ N)

(3) 3 : 4

$(1,1,5) \mathrm{kl}$

Qर. $14 \times 1$

(a) 24 *

$\langle 13,54 \%)$

\section{activanks}

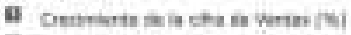

tisasaans

112 Beses)

L Bukdendates

Bas

b.a3

E Intactin de Retros rite

Ex

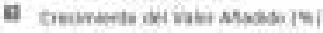

\section{moouctrvipue}

a ingingtain!

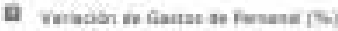

E Centeriote de Fossul

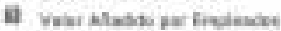

\section{CAsot plow}

a cain huse

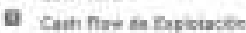

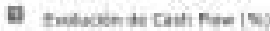

6. $-31-389,3$

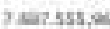

11.93

\section{aRNTAEIUIBND}

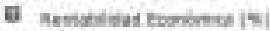

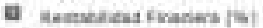

a Gana Randeros its?

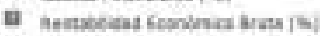

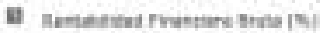

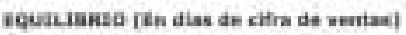

Q Conitas Centas icha me vemina!



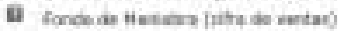

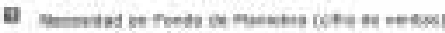

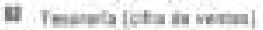

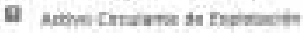

\section{весананы}

Q Nonde de Herwors

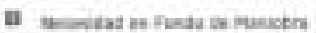

E) Tnevete

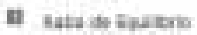

\section{sonvencth}




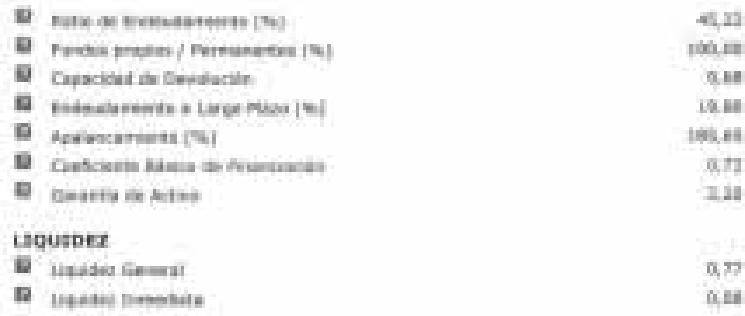

Grandes Masas Patrimenales Activo

\begin{tabular}{|c|c|c|}
\hline 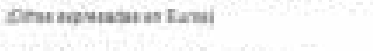 & $\begin{array}{l}32 / 123 / 3504 \\
121 \text { Maces! }\end{array}$ & $(\boldsymbol{\nabla})$ \\
\hline  & & \\
\hline ") INenonitzano & $40.602 .516,32$ & {$[30,34 *)$} \\
\hline $\begin{array}{l}\text { C) eastos a dastarbuta en vasuos } \\
\text { ejencictos }\end{array}$ & 2 2ara,30 & to,as *) \\
\hline 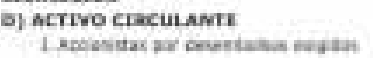 & cousesuan & 128,654 \\
\hline in Latheseas & 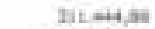 & $12,45=$ \\
\hline in Pendon & 2useseng 3 & $\operatorname{lin} m x$ \\
\hline 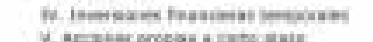 & 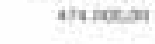 & 12.948 \\
\hline 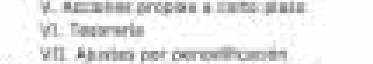 & 538.150 .92 & $n, 1=$ \\
\hline Totac ACTrVO $(a+B=c+B)$ & 50.535 .230 .91 & casos \\
\hline
\end{tabular}

Grandes Maras Parrimeniales - Active

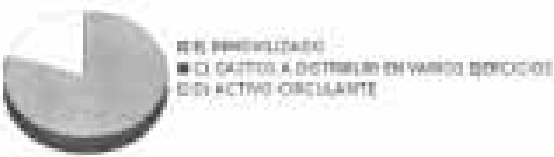

Grandes Masas Patrmariales Pastra

\begin{tabular}{|c|c|c|}
\hline 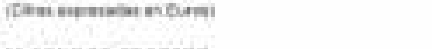 & $\begin{array}{l}31 / 32 / 2094 \\
\text { [5z Heses] }\end{array}$ & $\mid \mathbf{w i}$ \\
\hline a) rohbos nacosos & $27,220,293,48$ & (5x,Es $\mathbf{m})$ \\
\hline Lexick tendres & Easascaso & $\mid 25,2 x<1$ \\
\hline 11. hera a arenda & 1422.04 & paseisis \\
\hline 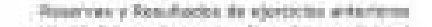 & j4.216.senti. & $(2,1) w)$ \\
\hline 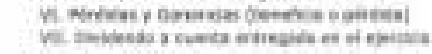 & 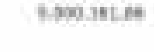 & $(7, F+\infty)$ \\
\hline
\end{tabular}




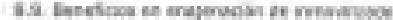




rebeascieren nintion.

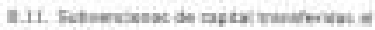
resasto in kirucos

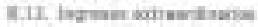

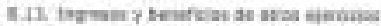


nesartvos

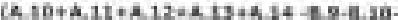

6.11-6.12:123]

a. V, Denorass awtes be makuestos

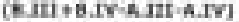

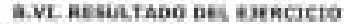

[Fesortias] [R. Y+A.1S+A.16)

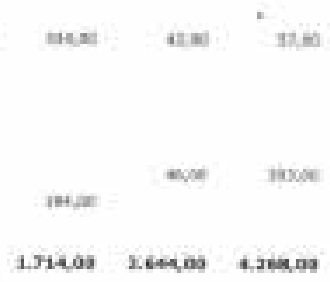

\section{Ex}

Eavetar a f xoel

\section{Principales Ratios}

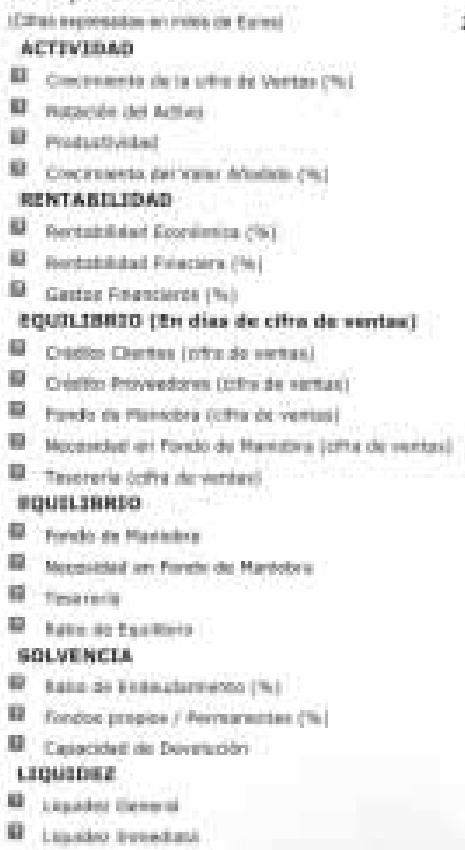

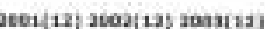

\begin{tabular}{|c|c|c|}
\hline $22,1=$ & $1 k, \dot{w}$ & ins: \\
\hline ent & $a y$ & iat \\
\hline 1.0 & tat. & $5, x$ \\
\hline isti & $\Delta s$ & An \\
\hline the & 1.3 & an \\
\hline $1=$ & 4,3 & 104 \\
\hline 4.48 & ist & $\ln$ \\
\hline at & jed & ant \\
\hline 32 & ais & 3ei \\
\hline 60 & 3 & an \\
\hline in & int & w \\
\hline 3 & a & is \\
\hline
\end{tabular}



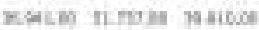

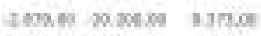

kw in ait

ther and and

4i. II the be te

1,ik th an

IAS L95 Lat

bir ase $a x$ 




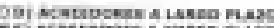

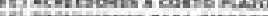

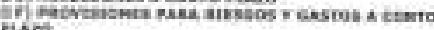

Cuenta Analitice ble Resuitsdn:

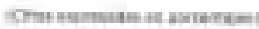



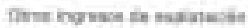

veiver te is hedaceiten

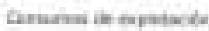

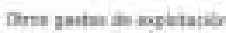

Vaits Anedo

chasis at yeness

Banitado Reanamice Buns

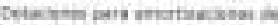
inrenteas:

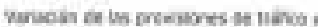

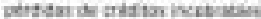

Aenaliats Erontimios Neta

irgoses Nuerteves

Uasosa Fuareis:

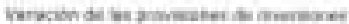
tisicion

Mesuitsato Asfividades Oeanarias

Jowes monithata

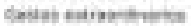

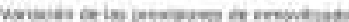



hesaitade henes Iwouestos

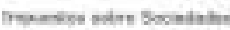

Geautzade Neba

bikinet ins anenrecorms in monetiati

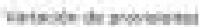

Rataflaeviasian net.

\begin{tabular}{|c|c|c|}
\hline $\begin{array}{r}\text { Enviess } \\
\text { 2003 }\end{array}$ & Lever & Draneneie \\
\hline 74.19 & tiverz & $2,3 i$ \\
\hline 6,61 & Ar & $T_{1}$ \\
\hline 100.90 & 100,00 & a.a \\
\hline xise & 26.3 & 4 \\
\hline 1.53 & 14,66 & $-4 t$ \\
\hline eq,a? & 20,91 & 0,9 \\
\hline 4t.ds & 48,73 & 40 \\
\hline 12,21 & 10,73 & 3,45 \\
\hline $\mathrm{kna}$ & $i=9$ & $a$, \\
\hline 0,21 & 109 & a.s \\
\hline 6.12 & 8,79 & 1.11 \\
\hline 0,30 & 225 & Iar \\
\hline $2-3$ & 47 & 6.4 \\
\hline sian & ats & A. \\
\hline$x \geqslant 1$ & 1,23 & $-1.5 \mathrm{a}$ \\
\hline its & $\ln$ & $t, m$ \\
\hline 4.26. & 1,74 & 1, 18 \\
\hline $1, \pi$ & 120 & 1,44 \\
\hline 1.ta & 2,69 & ans \\
\hline $94 ?$ & 1.68 & - \\
\hline 2,49 & 7,04 & 0,63 \\
\hline 211 & 4.43 & $17 \pi$ \\
\hline 200 & 4hen & Lit \\
\hline 6,53 & 9.36 & $-13 x$ \\
\hline
\end{tabular}


Matios

\begin{tabular}{|c|c|c|c|c|}
\hline 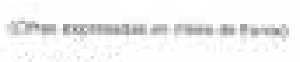 & $\begin{array}{l}\text { Ongresa } \\
2003\end{array}$ & Peleas & Modian & naters \\
\hline \multicolumn{5}{|l|}{ Activinao } \\
\hline ONonema teitaibs de verts & $=n$ & 35 & $24 \times$ & 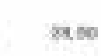 \\
\hline Rasubr efinest & biss & 2,4 & a,e &  \\
\hline havadn ex Actwn nes & 3.18 & $\alpha, E 2$ & 1.26 & ant \\
\hline 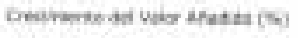 & asish & हैक $\$$ & 14,4 & ta.s. \\
\hline \multicolumn{5}{|l|}{ peoductrvanas } \\
\hline hedartsoital & 1,28 & 1,04 & 1.25 & 1,23 \\
\hline 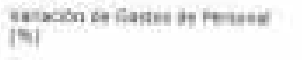 & indit & 3,41 & As, तa & 25,14 \\
\hline Conte reste st Mrawiul & axes & 22,12 & $36 \mathrm{~m}$ & $28 \%$ \\
\hline 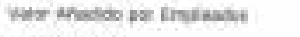 & in, n & 25,10 & $12 \times 3$ & as \\
\hline \multicolumn{5}{|l|}{ CASAH FLONG } \\
\hline$\Leftrightarrow n=$ & atses,an & kans:se & $13 . \operatorname{senc0}$ & 18. 3946 \\
\hline 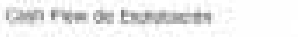 & atsedas & 2.21208 & 1134215 & 34.454 .43 \\
\hline 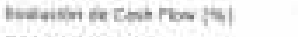 & an,54 & $-2,04$ & $\operatorname{lan}$ & In, n \\
\hline \multicolumn{5}{|l|}{ MEATABZLTDAD } \\
\hline 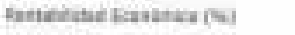 & $\operatorname{tin}$ & an & 4,57 & sit \\
\hline 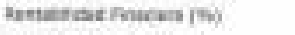 & 1,4 & 2,44 & 11,23 & 2k,43 \\
\hline 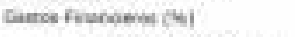 & 10 & 1,52 & 2,64 & 4.77 \\
\hline 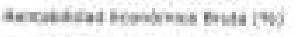 & 1.98 & 4,17 & $\operatorname{lag}$ & in.ia \\
\hline Aetukbas Frenoss stris ind & 20.95 & 24,75 & 78,40 & 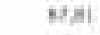 \\
\hline \multicolumn{5}{|l|}{$\begin{array}{l}\text { EQuituanto (En dias te } \\
\text { ofre de ventaa) }\end{array}$} \\
\hline 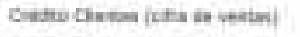 & the & $170 \%$ & $24+4 i$ & 294.67 \\
\hline 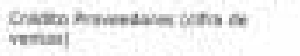 & ant & $2 \pi x+10$ & 205,15 & 325,62 \\
\hline 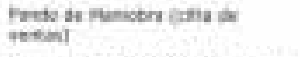 & ai & what & ss: 9 & 100,11 \\
\hline 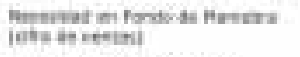 & \& & 0,9 & (at, 15 & 185.17 \\
\hline 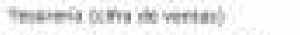 & is & $\ln , a$ & $-43,21$ & 6.11 \\
\hline \multicolumn{4}{|l|}{ equiruago } & atsis \\
\hline Fonten de Maviss:s & t4.3abe & Fr xed, 90 & $10 \pi 71,00$ & $\operatorname{arn}, \infty$ \\
\hline 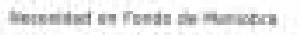 & Wanat & 1139,23 & n:40.00 & $\operatorname{rassc00}$ \\
\hline Teaserente & emant & 1e:31,15 & +19300 & A 34Lis \\
\hline Now be Dasibry & 1, 23 & $t w$ & 1,30 & in \\
\hline \multicolumn{5}{|l|}{ sotvencis } \\
\hline 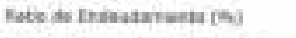 & esan & $x, 23$ & W.17: & 0,26 \\
\hline 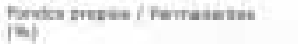 & 4t:at & x.m & 34,41 & $58.4 !$ \\
\hline
\end{tabular}




\begin{tabular}{|c|c|c|c|c|}
\hline 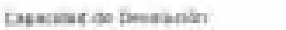 & 2.00 & $\tan$ & 2.91 & 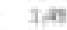 \\
\hline 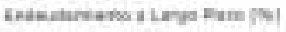 & 3.91 & 1.10 & $4 \pi m$ & $21, N$ \\
\hline Epavetarasoso $|\mathrm{W}|$ & neive & 422,22 & 462,14 & $\operatorname{lak}, 3 t$ \\
\hline 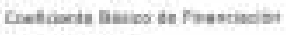 & 2.00 & 100 & int & ine \\
\hline ferronite os kntje & $t=4$ & 1,14 & 1,25 & 1,21 \\
\hline \multicolumn{5}{|l|}{ Hesaderz } \\
\hline Lsedent Cerein: & 2.30 & E.st & 3,17 & 3,st \\
\hline I I caites iareitata & 1.,18 & $1, \pi 2$ & on & Ett \\
\hline
\end{tabular}

Etwenith at Sele $1+1$ wat

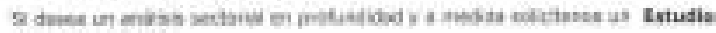
nnanewrosati

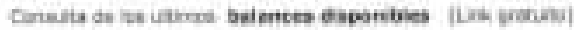


erspress.

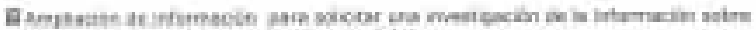

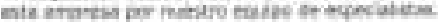

Cirviar exte informe:

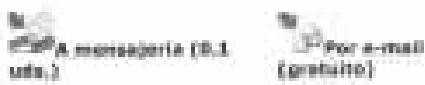

Par fark (40.d

ath.

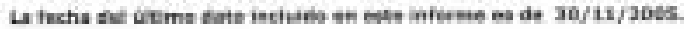

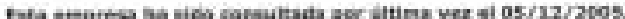

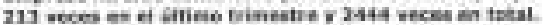

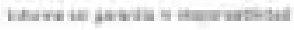

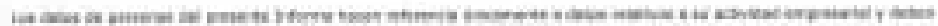
air

Informa 5.A.

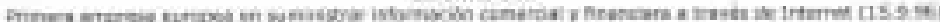

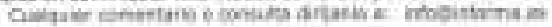

